\title{
RISK-AVERSE PREFERENCES IN A DUAL-CHANNEL SUPPLY CHAIN WITH TRADE CREDIT AND DEMAND UNCERTAINTY
}

\author{
ChOng Zhang, YaXian Wang ANd Lifan Zhang*
}

\begin{abstract}
Though it is an important means for enterprises to increase market demand and boost profits, trade credit can carry risks. Besides, risks also result from uncertain market demand. Decisionmakers' attitude towards risk will influence the decisions of enterprises, so it is meaningful to study the impact of risk preference on supply chain performance. This paper explores the effect of risk-averse preferences of the manufacturer or retailer on their delayed payment periods decision and utility when the dual-channel structure is adopted. Customer demands are uncertain and depend on the delayed payment periods that the manufacturer and the retailer may offer to them. Mean-variance model is used to describe the risks due to uncertain demand, and establishes supply chain utility models under four decision-making situations (both are risk-neutral; only the retailer is risk-averse; only the manufacturer is risk-averse; both are risk-averse). According to our study, supply chain members with higher risk aversion are more inclined to prolong delayed payment period. The retailers risk aversion is adverse for her utility, but beneficial to the manufacturers utility, thus a new coordination mechanism is proposed to achieve coordinate when only the retailer is risk averse. We prove that the contract can effectively improve the utility of the whole supply chain. This paper conduces to enrich the emerging literature on relating risk aversion preferences to trade credit period decision and coordination behavior under dual-channel environment.
\end{abstract}

Mathematics Subject Classification. 90B50, 91B24, 91A40.

Received June 26, 2019. Accepted November 12, 2020.

\section{INTRODUCTION}

With the development of Internet technology and the improvement of delivery efficiency of logistics service companies (UPS, DHL and FedEx), the network channel has become an important sale channel. For instance, by the end of 2013, more than 20000 e-Commerce websites had been formed in China, including Taobao.com which is the largest e-Commerce website with about six million online stores. A dual-channel mode that morphs the traditional offline channel with the online channel has been adopted by many brand manufacturers, such as BM, HP, Nike, Pioneer Electronics, and Estee Lauder, which have included a network channel into their traditional retail channel (see [51]). Therefore, it is of great significance for enterprises and academia to study the dual-channel supply chain.

Keywords. Supply chain management, dual-channel supply chain, delayed payment period, risk-averse preference, utility.

School of Management, Nanjing University of Posts and Telecommunications, 210003 Nanjing, P.R. China.

*Corresponding author: zlf9977@163.com 
It is widely acknowledged that trade credit has been applied in traditional retail channel for stimulating the order and market demand, but few studies incorporate it into dual-channel supply chain. As a matter of fact, an increasing number of manufacturers directly provide customers with a delayed payment period through the network channel to increase the sales volume. For example, Apple often provides the customers with a delayed payment period in its retail channel to stimulate demand. In the network channel, in order to eliminate customer concerns and stimulate demand, it also provides customers with payment methods such as delayed payment or installment payment. However, the delayed payment periods will have potential risks, such as the default risk of failing to pay for the goods or malicious returns, etc. So it is of practical significance to study how risk preference affects the decision-making of delayed payment periods in online and offline channels.

In existing studies, supply chain members are assumed to be risk-neutral. However, in the face of losses and gains of the same scale, people always hate losses more actually. Many empirical studies find it is difficult for traditional risk-neutral models to explain this preference (see [52]). That is to say that when making relevant decisions, supply chain members not only consider the maximization of their own profits, but also consider whether they can bear the risk of corresponding decisions. For example, if the risk is too high, the supply chain members would rather give up some of its profits in pursuit of a steady income. At present, the method often used to study risk aversion is the mean-variance (MV) approach. The MV method was first proposed by Harry Markowitz (see [43]), and it is the basic theory of financial risk management. MV method is a mature method for risk analysis to study decision making problems with risk concerns. Due to the uncertainty of demand, supply chain members often face certain financial risks, so the MV method has been used in many supply chain operation models to study risk management, such as Choi et al. [12], Chiu and Choi [11], Xue et al. [60] and Bai et al. [3].

Under the above background, this paper tries to formulate the following research questions: (1) How can the manufacturer and retailer make the optimal delayed payment periods to maximize utilities? (2) How does the risk aversion coefficient affect the decision of delayed payment periods and the utilities of the manufacturer and retailer? (3) How to design a coordination mechanism to improve the total profit of supply chain?

To address the above questions, we study decision problem of dual-channel supply chain on delayed payment periods with risk preference for a dominant manufacturer. Specifically, we consider the following: (1) the decisions on the delayed payment periods are taken under stochastic demand where the delayed payment periods that the manufacturer and the retailer offer to customers vary; (2) assume the demand is proportional to the delayed payment period of its own channel and inversely proportional to the delayed payment period of another channel; (3) a delayed payment coordination mechanism is proposed, which can improve the total profit of supply chain.

\section{Literature REVIEW}

\subsection{The dual-channel supply chain}

The literature provides some evidence of the richness on this research topic, especially on price competition and pricing under the dual-channel environment. Chiang et al. [8] analyzed the pricing game between the manufacturer and the retailer after opening the direct channel. Yao and Liu [63] investigated how an online channel of the manufacturer can cause price competition in two channels. Huang and Swaminathan [26] analyzed the pricing decision when the supplier sold products through two channels. Dan et al. [15] studied the determination of the service level and price of the retailer, further analyzed its effect on the performance under dual-channel environment. Lang et al. [34] proposed an improved revenue sharing contract to coordinate the dual-channel supply chain under cap-and trade mechanism. Others have studied the optimal price decisions in closed loop supply chains $[21,27,64]$.

As the dual-channel model may lead to conflicts and competition between the two channels, scholars $[1,6,19]$ have shown how to alleviate the conflicts and improve supply chain operations by using coordination mechanisms, such as trade credit, buyback contract, revenue sharing contract, and quantity discounts. In terms of contracts to coordinate the dual-channel supply chain, Boyaci [5] paid attention to the inventory level of the manufacturer's online channel and the retailer's offline channel. It is found that the previous simple coordination contract 
is difficult to achieve coordination, so a two-part compensation-commission contract is proposed. Geng and Mallik [17] studied the inventory strategy and coordination mechanism of dual-channel supply chain considering demand random and inventory competition. A reverse revenue-sharing contract is proposed for coordination.

Chiang [10] then proposed a new contract to coordinate the dual-channel supply chain by combining inventory cost sharing with direct channel revenue sharing. Liu [38] studied the joint production and pricing strategy under the dual-channel environment considering information asymmetry. Two contracts are proposed to coordinate the supply chain. Results found when uncertainty is lower, the manufacturer prefers a single contract. Hua et al. [23] introduced the revenue sharing contract into the product design issue and found that the contract could achieve coordination effectively. Chen et al. [9] showed that the coordination contract between the wholesale price and the network channel price could achieve coordination, albeit advantageous only to the retailer and not to the manufacturer. Based on it, a contract with a supplementary agreement (a two-party tariff or a profit-sharing contract) can achieve the status of mutual benefits. Qi et al. [45] proposed two different price discounts, that is, considering the linear relationship between retail prices of both channels and wholesale price to coordinate the dual-channel supply chain under the cap-and-trade mechanism.

\subsection{Risk preference}

The above studies assumed that the decision makers are risk neutral. In practice, with market competition and demand uncertainty, the risk attitude of decision makers may influence the decision-making process. Recently, researchers have explored how does risk attitudes of dual-channel supply chain decision makers affect decisionmaking behavior. The mean-variance model was first proposed by Markowitz [43].

This model has been widely used in literature and many industries to describe the degree of risk aversion. In addition, value at risk (VaR) and conditional value at risk (CVaR) are also applied in the financial field $[36,55]$. The prospect theory proposed by Kahneman and Tversky [29] is also used to describe the risk preference of decision makers (see [39]). Xie et al. [57] studies how risk preference affects quality and pricing decisions. And the decisions and performance under different power structures are compared.

$\mathrm{Xu}$ et al. [59] discussed the pricing decision and supply chain coordination under the risk preference of members. A two-way revenue sharing contract is proposed to achieve the outcome of win-win. Kim and Park [31] studied how the actors' risk aversion affects the price of the manufacturer under a dual-channel environment. Li et al. [37] analyzed the influence of retailer's risk preference on order quantity and profit under the policy of consistent price. The risk sharing contract is proposed for coordination. Liu et al. [40] compared the price decisions under information symmetry and information asymmetry, and price decisions under risk aversion and risk neutral. Results showed information asymmetry attenuated the efficiency of the supply chain. Yan et al. [61] combined risk aversion and fairness preference, and analyzed how the risk unfairness aversion coefficient affects the decisions and profits of enterprises. Moreover, a risk-sharing mechanism is proposed to achieve coordination.Other studies have also examined how actors' risk preference affect channel pricing in the dualchannel environment (see [36]).

All the above literature confirms that risk preference can affect the pricing decisions of dual channel members. According to our desk survey, it shows that the domain on dual-channel pricing, coordination and risk preference hasn't involved a delayed payment period.

\subsection{Delayed payment period}

In recent years, the delayed payment strategy has attracted much attention. It firstly proposed by Goyal [20] in an economic order quantity model with permissible delayed payments. A delayed payment strategy is an important short-term financing instrument used by firms. According to the Financial Times, $90 \%$ of the global merchandise trade in 2007 was conducted based on delayed payments (see [32]). The delayed payment strategy can effectively reduce the cost of purchase after factoring in the time value of money. In short, now customers can buy' more. Further, the delayed payment strategy as a price discounting instrument can increase the sales volume. In short, a delayed payment strategy can alter market demand and influence the actors' utility. The 
TABLE 1. Summary of related studies.

\begin{tabular}{|c|c|c|c|c|c|c|c|c|}
\hline \multirow[t]{2}{*}{ Source } & \multirow{2}{*}{ Risk preference } & \multicolumn{2}{|c|}{ Demand type } & \multicolumn{2}{|c|}{ Demand dependence } & \multirow{2}{*}{$\begin{array}{l}\text { Coordination } \\
\text { contract }\end{array}$} & \multicolumn{2}{|c|}{ Credit period } \\
\hline & & Det. & Stoch. & Price & Credit & & Fix. & Decis. \\
\hline $\begin{array}{l}\text { Huang and } \\
\text { Swaminathan [26] }\end{array}$ & & $\sqrt{ }$ & & $\sqrt{ }$ & & & & \\
\hline Hua et al. [23] & & $\sqrt{ }$ & & $\sqrt{ }$ & & & $\sqrt{ }$ & \\
\hline Xie et al. [57] & $\sqrt{ }$ & & $\sqrt{ }$ & $\sqrt{ }$ & & & & \\
\hline Chen et al. [9] & & $\sqrt{ }$ & & $\sqrt{ }$ & & & $\sqrt{ }$ & \\
\hline Dan et al. [15] & & $\sqrt{ }$ & & $\sqrt{ }$ & & & $\sqrt{ }$ & \\
\hline $\begin{array}{l}\text { Bai et al. }[3] \\
\text { Teng et al. [49] }\end{array}$ & $\sqrt{ }$ & $\sqrt{ }$ & $\sqrt{ }$ & $\sqrt{ }$ & $\sqrt{ }$ & $\sqrt{ }$ & $\sqrt{ }$ & $\sqrt{ }$ \\
\hline Li et al. $[36]$ & $\sqrt{ }$ & & $\sqrt{ }$ & $\sqrt{ }$ & & & & \\
\hline $\mathrm{Xu}$ et al. [59] & $\sqrt{ }$ & & $\sqrt{ }$ & $\sqrt{ }$ & & & $\sqrt{ }$ & \\
\hline Li et al. [37] & $\sqrt{ }$ & & $\sqrt{ }$ & $\sqrt{ }$ & & & $\sqrt{ }$ & \\
\hline Lang et al. [34] & & $\sqrt{ }$ & & $\sqrt{ }$ & & & $\sqrt{ }$ & \\
\hline Qi et al. [46] & & $\sqrt{ }$ & & $\sqrt{ }$ & & & $\sqrt{ }$ & \\
\hline Yan et al. [62] & $\sqrt{ }$ & & $\sqrt{ }$ & & & & $\sqrt{ }$ & \\
\hline Our study & $\sqrt{ }$ & & $\sqrt{ }$ & & $\sqrt{ }$ & $\sqrt{ }$ & $\sqrt{ }$ & $\sqrt{ }$ \\
\hline
\end{tabular}

Notes. Det. refers to deterministic; Stoch. refers to stochastic; Fix. refers to fixed parameter and Decis. refers to decision variable.

delayed payment strategy may affect the purchase behavior of customers. Research suggests that customers tend to purchase larger lots if the delayed payment period is provided [18,33]. Additionally, some evidence points show that offering a delay in payment could stimulate greater demand from customers $[24,25,48]$. Recently, some scholars have studied the combination of delayed payment and competition, risk, and financing. For instance, Yang and Birge [62] studied coordination considering the combined effects of delayed payments, risk sharing, and financing, and showed how delayed payments can strengthen the utility of the supply chain actors by a risk sharing mechanism and further explored the combined effect of delayed payments and bank financing on the supply chain performance. Lee et al. [35] studied how a delayed payment affects the market competition and performance between actors in the supply chain. Peura et al. [44] analyzed the influence of delayed payments under horizontal competition. By analyzing the price decisions made by two firms, they showed that delayed payments can ameliorate horizontal price competition, when there is insufficient working capital. Both the manufacturer and the retailer can offer delayed payment periods relative to the retailer and customers to reduce their financial pressure and increase market demand. There is a competition on the delayed payment periods between online channel and retail channel. Only a few studies have introduced delayed payments in the dualchannel environment, albeit without setting the delayed payment period as a decision variable nor setting the demand to depend on the delayed payment period.

Table 1 presents the literature applicable to our research.

\section{Problem Description And notations}

\subsection{Problem description}

The market structure studied in this paper follows the research of Chiang et al. [8], Tsay and Agrawal [51] and Liu et al. $[40,41]$ considering a supply chain that includes a monopoly manufacturer and an exclusive retailer (see Fig. 1). Both the actors may be risk-neutral or risk-averse. The manufacturer produces a product and sells 


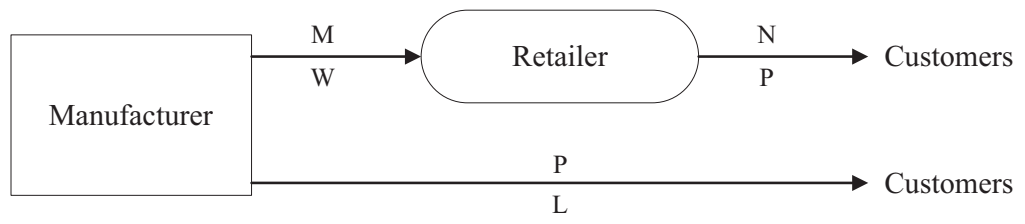

FIGURE 1. Supply chain structures studied in this paper.

it through two channels - retail and direct (see Fig. 1). Demand of the two channels is random and hard to predict because of the individual needs of customers.

A make-to-order (MTO) strategy is adopted by the manufacturer to produce products and sell them to the retailer and customers in a single sales period. Thus, inventory and shortage costs are not considered. This assumption is reasonable, because MTO can bring many benefits to the enterprise. On the one hand, MTO can promote service quality provided to customers, so as to attract more customers. On the other hand, MTO can also avoid a large inventory backlog and realize inventory-free production. In the highly developed information technology today, MTO can make enterprises directly face the market and enhance their competitiveness. For example, more and more clothing brands have started the business of clothing customization to better meet the needs of consumers. MTO has also been widely used in previous literature $[3,8]$.

Due to the rapid development of e-commerce, channel prices have gradually become the focus of attention of enterprises. Suning Commerce Group took the lead in adopting the online and offline marketing mode with the same price among large retail giants. Since then, the dual channel with the same pricing mechanism has become a trend. Therefore, we assume that the retail prices of the two channels are the same. In order to stimulate demand and enhance competitiveness, the manufacturer and the retailer give end customers a delay payment period. It has been proved that the increase of delay payment period can significantly increase the purchase intention of customers. However, the manufacturer or retailer will lose part of the opportunity cost of capital during the delay payment period.

In reality, increasing the price lowers market demand, while the delay payment period increases market demand. In the stochastic demand environment, we denote by $D_{r}$ and $D_{m}$ the market demand of the retail channel and direct channel respectively. Following the existing literature, e.g., Huang and Swaminathan [26], $\mathrm{Xu}$ et al. [58] and Choi et al. [13], we model the stochastic market demand as follows.

$$
\begin{aligned}
D_{r} & =\delta \widetilde{a}+b_{1} N-\theta_{1} L \\
D_{d} & =(1-\delta) \widetilde{a}+b_{2} L-\theta_{2} N .
\end{aligned}
$$

As shown, the demands are directly proportional to the delayed payment period of their own channel and inversely proportional to the delayed payment period of another channel. $\widetilde{a}(\widetilde{a}>0)$ is the basic market demand and $\delta(0<\delta<1)$ is the market share of the retail channel, $1-\delta$ is the market share of the direct channel. $b_{1}$ and $b_{2}$ are the influence coefficients of the delayed payment periods to the demand. $\theta_{1}$ and $\theta_{2}$ refer to the cross delayed payment periods influence coefficient to the demand. According to the demand function in Khouja et al. [30], Cai [7] and Hua et al. [22], for facilitating solutions of the following model, we set $\theta_{1}=\theta_{2}=\theta$ and $b_{1}, b_{2}>\theta>0$, where $b_{1}, b_{2}>\theta>0$ means that the delayed payment period of one's own channel has a greater impact. To reflect the uncertainty of the market demand, supposing $\widetilde{a}$ is a random variable, written as $\widetilde{a}=a+\xi$, where $\widetilde{a}$ denotes the potential overall size of the market and $\xi \sim N\left(0, \sigma^{2}\right)$. The detailed description about the demand function is shown in Appendix A.

Although trade credit is widely used among enterprises, it also faces certain risks. The main risks include two types: buyer's demand risk and payment time risk. For example, Circuit City, the second largest consumer electronics retailer in the United States, declared bankruptcy in November 2008 due to continued low sales. Among them, three major trade creditors (HP, Samsung and Sony) have a total debt of $\$ 284$ million (see [14]). 
Additionally, the more common risk is the payment time risk. It is very common to extend the payment time beyond the agreed terms of trade credit. For example, in 2012, large British companies paid an average of more than 20 days beyond the terms of the agreement (see [28]). These are collectively referred to as default risk. Therefore, when trade credit is provided, certain default risk needs to be considered. And the default risk increases as the delayed payment period increases. The relevant default risk function can be referred to Lou and Wang [42], Wu et al. [56] and Vandana and Kaur [53]. Thus, the default risk functions of the delayed payment periods $M, N$ and $L$ are as follows.

$$
F(M)=1-e^{-\gamma M}, F(N)=1-e^{-\gamma N}, F(L)=1-e^{-\gamma L}
$$

where $\gamma(\gamma>0)$ is the default risk coefficient, which is a positive constant.

\subsection{Notations.}

For convenience, the subscript $i$ denotes the following: $i=1$ refers to both risk neutral manufacturer and retailer; when $i=2$, only the retailer has a risk preference; when $i=3$, only the manufacturer has a risk preference; and when $i=4$, both actors have a risk preference. The superscripts $m, r$ and $s c$ represents the manufacturer, retailer, and entire supply chain respectively. In addition, the superscript $*$ denotes optimality.

Next, $C$ denotes the unit production cost. $W$ denotes the manufacturer's wholesale price to the retailer. Next, $M$ is the delayed payment period offered by the manufacturer to the retailer. $N / L$ is the delayed payment period offered by the retailer/manufacturer to the customers respectively. $\pi_{i}$ denotes the supply chain member's profit. $U_{i}$ is the supply chain member's utility per year. The sale price of the two channel are both equal to $P$. Without loss of generality, we set $P>W>C$.

\section{MODEL DESCRIPTION}

\subsection{Basic model}

When the dominated manufacturer and the retailer are both risk neutral, the manufacturer first determines the optimal delayed payment period $L$ and followed by the retailer determines the optimal delayed payment period $N$.

According to the assumptions, the retailer's sales revenue after default risk is $P D_{r}(1-F(N)$. Additionally, the retailer will have an extra capital opportunity cost and income, i.e., $P N I D_{r}$ and $W M I D_{r}$, for the delayed payment period $N$ and $M$. Meanwhile, for the manufacturer, the profit of the manufacturer includes two aspects: traditional retail channel and network channel. The manufacturer will bear the opportunity cost of capital $W M I D_{r}$ and $P L I D_{d}$. Based on Taylor [47] and Tsao [50], we do not consider inventory and shortage costs. Therefore, the retailer's and the manufacturer's profit can be pressed as

$$
\begin{aligned}
E\left(\pi^{r}\right) & =P D_{r}\left(1-F(N)-W D_{r}+W M I D_{r}-P N I D_{r}\right. \\
E\left(\pi^{m}\right) & =W D_{r}\left(1-F(M)-C D_{r}-P D_{d}(1-F(L))-C D_{d}-W M I D_{r}-P L I D_{d} .\right.
\end{aligned}
$$

\subsection{Risk preference model}

Risk preference is a form of social preference behavior, implying that a person's attitude to risk may affect their decision-making. When striving to maximize personal interests, humans will consider their risk tolerance. Some people even opt to sacrifice their personal interests to avoid risk.

To study how risk aversion affects performance, we use MV method to construct utility function, which is like those found in Gan et al. [16], Wei et al. [54] and Bai et al. [3]. Using the mean-variance model, the following insights are gained.

(a) When the retailer has a risk preference, the retailer's utility function is given by:

$$
U^{r}=E\left(\pi^{r}\right)-K_{r} \sqrt{\operatorname{Var}\left(\pi^{r}\right)} .
$$


(b) When the manufacturer has a risk preference, the manufacturer's utility function is given by:

$$
U^{m}=E\left(\pi^{m}\right)-K_{m} \sqrt{\operatorname{Var}\left(\pi^{m}\right)}
$$

where $K_{r}\left(K_{r}>0\right)$ represents the risk aversion degree of the retailer, and $K_{m}\left(K_{m}>0\right)$ represents the risk aversion degree of the manufacturer respectively. As $K_{r}\left(K_{m}\right)$ increases, the retailer (manufacturer)'s risk aversion increases. Risk neutrality for retailer (manufacturer) is assured when $K_{r}\left(K_{m}\right)=0$. Next, the optimal decisions for the supply chain are made under the four decision instances.

\section{OPTIMAL DECISIONS ON SUPPLY CHAIN UNDER SEVERAL DECISION INSTANCES}

We now present the utilities of the supply chain under the four decision instances.

\subsection{Manufacturer and retailer are both risk neutral}

According to the mean-variance model, $K_{r}=K_{m}=0$, and the utility of the retailer and the manufacturer are obtained from equations (4.3) and (4.4), yielding:

$$
\begin{aligned}
U_{1}^{r}=E\left(\pi^{r}\right)= & \left(P e^{-\gamma M}+W M I-W-P N I\right)\left(\delta a+b_{1} N-\theta L\right) \\
U_{1}^{m}=E\left(\pi^{m}\right)= & \left(W e^{-\gamma M}-C-W M I\right)\left(\delta a+b_{1} N-\theta L\right) \\
& +\left(W e^{-\gamma L}-C-P L I\right)\left[(1-\delta) a+b_{2} L-\theta N\right] .
\end{aligned}
$$

Solving equations (5.1) and (5.2) by the backward induction method. The following result are obtained.

Proposition 5.1. When both actors are risk neutral, the optimal delayed payment periods are given by

$$
\begin{aligned}
L_{1}= & \frac{\left(2 b_{1} b_{2}-\theta-b_{1} \theta\right)(W-C)+b_{1} \theta W M(\gamma+I)}{(W \gamma+P I)\left(4 b_{1} b_{2}-2 \theta^{2}\right)} \\
& -\frac{2 b_{1} P(a-\delta a)(\gamma+I)+\delta a \theta P(\gamma+I)+b_{1} \theta(P-W+W M I)}{4 b_{1} b_{2} P(\gamma+I)-2 P \theta^{2}(\gamma+I)} \\
N_{1}= & \frac{-\delta a}{2 b_{1}}+\frac{P-W+W M I}{2 P(\gamma+I)}+\frac{\left(2 b_{1} b_{2}-\theta-b_{1} \theta\right)(W-C)+b_{1} \theta W M(\gamma+I)}{2 b_{1}(W \gamma+P I)\left(4 b_{1} b_{2}-2 \theta^{2}\right)} \\
& -\frac{2 b_{1} P(a-\delta a)(\gamma+I)+\delta a \theta P(\gamma+I)+b_{1} \theta(P-W+W M I)}{8 b_{1}^{2} b_{2} P(\gamma+I)-4 b_{1} P \theta^{2}(\gamma+I)} .
\end{aligned}
$$

Proposition 5.1, if $N_{1}$ is non-negative, the optimal delayed payment period is $N_{1}^{*}=N_{1}$ as shown in equation (5.4). If $N_{1}<0$, the optimal delayed payment period is $N_{1}^{*}=0$. Similarly, if $L_{1}$ is non-negative, the optimal delayed payment period is $L_{1}^{*}=L_{1}$, else $L_{1}^{*}=0$.

Proposition 5.1 can be explained as follows. $N_{1}$ and $L_{1}$ refer to the delayed payment periods, whereby the conditions $N_{1} \geq 0$ and $L_{1} \geq 0$ should be satisfied. If $N_{1}<0$ or $L_{1}<0, N_{1}$ and $L_{1}$ reflect the advance payment periods; hence, $N_{1}^{*}=0$ and $L_{1}^{*}=0$.

The proof of Proposition 5.1 and the other propositions and corollaries are given in the Appendix A. From Proposition 5.1, we can get Corollary 5.2:

\section{Corollary 5.2.}

(1) $\frac{\mathrm{d} N_{1}^{*}}{\mathrm{~d} I}<0, \frac{\mathrm{d} N_{1}^{*}}{\mathrm{~d} \gamma}<0, \frac{\mathrm{d} N_{1}^{*}}{\mathrm{~d} C}<0, \frac{\mathrm{d} N_{1}^{*}}{\mathrm{~d} M}>0$;

(2) $\frac{\mathrm{d} L_{1}^{*}}{\mathrm{~d} I}<0, \frac{\mathrm{d} L_{1}^{*}}{\mathrm{~d} \gamma}<0, \frac{\mathrm{d} L_{1}^{*}}{\mathrm{~d} C}<0, \frac{\mathrm{d} L_{1}^{*}}{\mathrm{~d} M}>0$. 
Corollary 5.2 indicates that when the production cost increases, the manufacturer will shorten the delayed payment period to the customers for reducing his cost, and the delayed payment period of the retailer to customers will also be shortened to improve the cash flow. The increasing delayed payment period result in the higher default risk and the opportunity cost, which means the manufacturer will bear more risks from delayed payments and greater interest cost. In other words, the manufacturer shortens the delayed payment period to the customers, which means the retailer's risk is being increased. So, the retailer also shortens the delayed payment period. When the delayed payment period by the manufacturer to the retailer increases, the retailer has more available funds and can, therefore, provide a longer delayed payment period to customers for increasing sales. At the same time, the manufacturer will also increase the delayed payment period of the network channel for competing with the traditional retail channel. Therefore, the manufacturer's delayed payment period available to the customers will be extended.

Thus, if both parties are risk neutral, the retailer and the manufacturer determine the optimal solutions through game competition, and the optimal utility of both the retailer and manufacturer are given as $U_{1}^{r^{*}}\left(N_{1}^{*}, L_{1}^{*}\right)$ and $U_{1}^{m^{*}}\left(N_{1}^{*}, L_{1}^{*}\right)$ respectively.

\subsection{Only retailer has a risk preference}

When only the retailer has a risk preference, the retailer's expected profit and the profit variance are respectively

$$
\begin{aligned}
E\left(\pi^{r}\right)= & \left(P e^{-\gamma N}+W M I-W-P N I\right)\left(\delta a+b_{1} N-\theta L\right) \\
\operatorname{Var}\left(\pi^{m}\right)= & E\left(\pi_{m}-E\left(\pi_{m}\right)\right)^{2}=\left[\left(W e^{-\gamma M}-C-W M I\right) \delta \sigma\right. \\
& \left.+\left(W e^{-\gamma L}-C-P L I\right)(1-\delta) \sigma\right]^{2} .
\end{aligned}
$$

According to equation (4.3), the retailer's utility is

$$
\begin{aligned}
U_{2}^{r} & =E\left(\pi^{r}\right)-K_{r} \sqrt{\operatorname{Var}\left(\pi^{r}\right)} \\
& =\left(P e^{-\gamma N}+W M I-W-P N I\right)\left(\delta a+b_{1} N-\theta L-\delta \sigma K_{r}\right) .
\end{aligned}
$$

As the manufacturer has no risk preference, $U_{2}^{m}=U_{1}^{m}$. From equation (5.2), the manufacturer's utility is then

$$
\begin{aligned}
U_{2}^{m}= & \left(W e^{-\gamma M}-C-W M I\right)\left(\delta a+b_{1} N-\theta L\right) \\
& +\left(W e^{-\gamma L}-C-P L I\right)\left[(1-\delta) a+b_{2} L-\theta N\right] .
\end{aligned}
$$

Solving equations (5.5) and (5.6) by the backward induction method. The following result are obtained.

Proposition 5.3. When only the retailer has a risk preference, the optimal delayed payment periods are given by

$$
\begin{aligned}
L_{2}= & \frac{\left(2 b_{1} b_{2}-\theta-b_{1} \theta\right)(W-C)+b_{1} \theta W M(\gamma+I)}{(W d+P I)\left(4 b_{1} b_{2}-2 \theta^{2}\right)} \\
& -\frac{2 b_{1} P(a-\delta a)(\gamma+I)+\left(\delta a \theta-\delta \sigma \theta K_{r}\right) P(\gamma+I)+b_{1} \theta(P-W+W M I)}{4 b_{1} b_{2} P(\gamma+I)-2 P \theta^{2}(\gamma+I)} \\
N_{2}= & \frac{\delta \sigma K_{r}-\delta a}{2 b_{1}}+\frac{P-W+W M I}{2 P(\gamma+I)}+\frac{\left(2 b_{1} b_{2}-\theta-b_{1} \theta\right)(W-C)+b_{1} \theta W M(\gamma+I)}{2 b_{1}(W d+P I)\left(4 b_{1} b_{2}-2 \theta^{2}\right)} \\
& -\frac{2 b_{1} P(a-\delta a)(\gamma+I)+\left(\delta a \theta-\delta \sigma \theta K_{r}\right) P(\gamma+I)+b_{1} \theta(P-W+W M I)}{8 b_{1}^{2} b_{2} P(\gamma+I)-4 b_{1} P \theta^{2}(\gamma+I)} .
\end{aligned}
$$


If $N_{2} \geq 0$, then $N_{2}^{*}=N_{2}$ as shown in equation (5.8); otherwise, $N_{2}^{*}=0$. Similarly, if $L_{2} \geq 0, L_{2}^{*}=L_{2}$, else $L_{2}^{*}=0$. The explanation of Proposition 5.3 is similar to that of Proposition 5.1.

From Proposition 5.3, we can get Corollary 5.4:

\section{Corollary 5.4.}

(1) $L_{2}^{*}>L_{1}^{*}, \quad N_{2}^{*}>N_{1}^{*}$.

(2) $\frac{\mathrm{d} L_{2}^{*}}{\mathrm{~d} K_{r}}>0, \frac{\mathrm{d} N_{2}^{*}}{\mathrm{~d} K_{r}}>0$.

(3) $\frac{\mathrm{d} L_{2}^{*}}{\mathrm{~d} K_{r}}<\frac{\mathrm{d} N_{2}^{*}}{\mathrm{~d} K_{r}}, N_{2}^{*}-N_{1}^{*}>L_{2}^{*}-L_{1}^{*}$.

Corollary 5.4 suggests that when the retailer has a risk preference, the retailer is more sensitive to market risk, so the delayed payment period offered by the retailer to customers will increase in order to keep' the demand and lower the risk. Therefore, when the retailer has a risk preference, the delayed payment period is now longer than that offered by a risk-neutral retailer, and the delayed payment period will increase as risk aversion coefficient. As the delayed payment period offered by the retailer to customers increases, it will have a negative effect on the demand of network channel. Therefore, the manufacturer will also increase the delayed payment period of the network channel in order to expand his market and compete with the traditional retail channel.

In addition, the retailer is more sensitive to risk as risk aversion. Thus, comparing with the risk neutral retailer, the increase in the delay payment period offered by the retailer to customers in traditional retail channel is greater than that offered by the manufacturer to customers in network channel.

Therefore, when only the retailer has a risk preference, the actors shall determine the optimal solutions through game competition. In such circumstance, the optimal actors' utility are $U_{2}^{r^{*}}\left(N_{2}^{*}, L_{2}^{*}\right)$ and $U_{2}^{m^{*}}\left(N_{2}^{*}, L_{2}^{*}\right)$ respectively.

From Proposition 5.4, we can get Corollary 5.5:

\section{Corollary 5.5.}

(1) $L_{2}^{*}>L_{1}^{*}, \quad N_{2}^{*}>N_{1}^{*}$.

(2) $\frac{\mathrm{d} L_{2}^{*}}{\mathrm{~d} K_{r}}>0, \frac{\mathrm{d} N_{2}^{*}}{\mathrm{~d} K_{r}}>0$.

(3) $\frac{\mathrm{d} L_{2}^{*}}{\mathrm{~d} K_{r}}<\frac{\mathrm{d} N_{2}^{*}}{\mathrm{~d} K_{r}}, N_{2}^{*}-N_{1}^{*}>L_{2}^{*}-L_{1}^{*}$.

Corollary 5.5 suggests that when only the retailer has a risk preference and certain conditions are met, compared to the risk neutral retailer, the retailer's utility decreases while the manufacturer's utility increases. As the retailer has a risk preference, in order to expand the demand and increase the competitiveness, both the retailer and the manufacturer will extend the delayed payment period available to customers respectively. However, a higher risk aversion coefficient means that the retailer will undertake more risk, leading to a lower utility. At that time, the utility of the manufacturer involves the utility of the two channels. As the increase of the delayed payment period by the retailer to customers outweighs that of the manufacturer to customers, the demand of retail channel increases while the demand of network channel reduces. When the increase of the utility of retail channel outweighs that of network channel, the utility of the manufacturer will increase.

Therefore, under certain conditions, only the manufacturer can gain an advantage from the retailer's risk preference. Under this circumstance, the manufacturer can exact greater utility with the increased demand from the retail channel. Furthermore, the manufacturer prefers cooperating with the retailer with high risk aversion coefficient to obtain greater utility from retail channel. 


\subsection{Only manufacturer has a risk preference}

When only the manufacturer has a risk preference, the expected profit of the manufacturer are respectively

$$
\begin{aligned}
E\left(\pi^{m}\right)= & \left(W e^{-\gamma M}-C-W M I\right)\left(\delta a+b_{1} N-\theta L\right) \\
& +\left(W e^{-\gamma L}-C-P L I\right)\left[(1-\delta) a+b_{2} L-\theta N\right] .
\end{aligned}
$$

And the profit variance of the manufacturer are

$$
\begin{aligned}
\operatorname{Var}\left(\pi^{m}\right) & =E\left(\pi_{m}-E\left(\pi_{m}\right)\right)^{2} \\
& =\left[\left(W e^{-\gamma M}-C-W M I\right) \delta \sigma+\left(W e^{-\gamma L}-C-P L I\right)(1-\delta) \sigma\right]^{2} .
\end{aligned}
$$

According to equation (4.4), the manufacturer's utility can be found from:

$$
\begin{aligned}
U_{3}^{m}= & E\left(\pi^{m}\right)-K_{m} \sqrt{\operatorname{Var}\left(\pi^{m}\right)}=\left(W e^{-\gamma M}-C-W M I\right)\left(\delta a+b_{1} N-\theta L\right. \\
& \left.-\delta \sigma K_{m}\right)+\left(W e^{-\gamma L}-C-P L I\right)\left[(1-\delta) a+b_{2} L-\theta N-(1-\delta) \sigma K_{m}\right] .
\end{aligned}
$$

The retailer has no risk preference and $U_{3}^{r}=U_{1}^{r}$. Thus, the retailer's utility is

$$
U_{3}^{r}=U_{1}^{r}=E\left(\pi^{r}\right)=\left(P e^{-\gamma N}+W M I-W-P N I\right)\left(\delta a+b_{1} N-\theta L\right) .
$$

Solving equations (5.9) and (5.10) by the backward induction method. The following result are obtained.

Proposition 5.6. When only the manufacturer has a risk preference, the optimal delayed payment periods are given by

$$
\begin{aligned}
L_{3}= & \frac{\left(2 b_{1} b_{2}-\theta-b_{1} \theta\right)(W-C)+b_{1} \theta W M(\gamma+I)}{(W \gamma+P I)\left(4 b_{1} b_{2}-2 \theta^{2}\right)}-\frac{2 b_{1}(a-\delta a)+\delta a \theta}{4 b_{1} b_{2}-2 \theta^{2}} \\
& -\frac{b_{1} \theta(P-W+W M I)-2 b_{1}(1-\delta) \sigma K_{m} P(\gamma+I)}{4 b_{1} b_{2} P(\gamma+I)-2 P \theta^{2}(\gamma+I)} \\
N_{3}= & \frac{-\delta a}{2 b_{1}}+\frac{P-W+W M I}{2 P(\gamma+I)}+\frac{\left(2 b_{1} b_{2}-\theta-b_{1} \theta\right)(W-C)+b_{1} \theta W M(\gamma+I)}{2 b_{1}(W \gamma+P I)\left(4 b_{1} b_{2}-2 \theta^{2}\right)} \\
& -\frac{2 b_{1}(a-\delta a)+\delta a \theta}{8 b_{1}^{2} b_{2}-4 b_{1} \theta^{2}}-\frac{b_{1} \theta(P-W+W M I)-2 b_{1}(1-\delta) \sigma K_{m} P(\gamma+I)}{8 b_{1}^{2} b_{2} P(\gamma+I)-4 b_{1} P \theta^{2}(\gamma+I)} .
\end{aligned}
$$

If $N_{3} \geq 0, \quad N_{3}^{*}=N_{3}$ as shown in equation (5.12); otherwise, $N_{3}^{*}=0$. Similarly, if $L_{3} \geq 0, L_{3}^{*}=L_{3}$, else, $L_{3}^{*}=0$. The explanation of Proposition 5.6 is similar to that of Proposition 5.1.

From Proposition 5.6, we can get Corollary 5.7:

\section{Corollary 5.7.}

(1) $L_{3}^{*}>I_{1}^{*}, N_{3}^{*}>N_{1}^{*}$.

(2) $\frac{\mathrm{d} L_{3}^{*}}{\mathrm{~d} K_{m}}>0, \frac{\mathrm{d} N_{3}^{*}}{\mathrm{~d} K_{m}}>0$.

(3) If $b_{1}>1 / 2, \frac{\mathrm{d} L_{3}^{*}}{\mathrm{~d} K_{m}}>\frac{\mathrm{d} N_{3}^{*}}{\mathrm{~d} K_{m}}, N_{3}^{*}-N_{1}^{*}<L_{3}^{*}-L_{1}^{*}$.

Corollary 5.7 suggests that, compared with a risk neutral manufacturer, the actors will choose to extend the delayed payment periods to the customers for increasing demand and the channel competitiveness, when only the manufacturer has a risk preference. Thus, the delayed payment periods that the manufacturer and retailer may offer to the customers will increase along with the risk aversion coefficient. Comparing the risk preference 
manufacturer and risk neutral manufacturer, the manufacturer increases the delay payment period outweighs that of the retailer.

Thus, when only the manufacturer has a risk preference, both parties determine the optimal solutions through game competition and the optimal actors' utility are $U_{3}^{r^{*}}\left(N_{3}^{*}, L_{3}^{*}\right)$ and $U_{3}^{m^{*}}\left(N_{3}^{*}, L_{3}^{*}\right)$ respectively.

Corollary 5.8 can be deduced as follows:

Corollary 5.8. If $\theta>1 / 2$, then

(1) $\frac{\mathrm{d} U_{3}^{m^{*}}}{\mathrm{~d} K_{m}}<0, U_{3}^{m^{*}}<U_{1}^{m^{*}}$.

(2) $\frac{\mathrm{d} U_{3}^{r^{*}}}{\mathrm{~d} K_{m}}<0, U_{3}^{r^{*}}<U_{1}^{r^{*}}$.

Corollary 5.8 suggests that when only the manufacturer has a risk preference and the coefficient of cross elasticity, $\theta$, is such that $\theta>1 / 2$, the actors' utility will decrease comparing with the risk neutral manufacturer. As the manufacturer has a risk preference, the manufacturer increases the delayed payment period for the customers for stimulating their demand. However, a higher risk aversion coefficient means that the manufacturer will be more risk-averse, which is unfavorable for the manufacturer. To seize the market, the retailer will choose to extend the delayed payment period provided to customers. Compared to the risk neutral manufacturer, the increase in the delayed payment period by the retailer to customers is less than that by the manufacturer, so the demand of the traditional retail channel lessens as $\theta$ increases; thus, the utility of the retailer reduces.

That is, if $\theta>1 / 2$ is satisfied, the manufacturer's risk preference is unfavorable to both actors' utilities. Therefore, when the manufacturer has a risk preference, the manufacturer should try to reduce the risk aversion coefficient and increase risk tolerance to improve the actors' utilities.

\subsection{Both retailer and manufacturer have a risk preference}

Under this decision instance, the utility functions are shown in equations (5.13) and (5.14) respectively:

$$
\begin{aligned}
U_{4}^{r}= & U_{2}^{r}=E\left(\pi^{r}\right)-K_{r} \sqrt{\operatorname{Var}\left(\pi^{r}\right)}=\left(P e^{-\gamma N}+W M I-W-P N I\right)\left(\delta a+b_{1} N-\theta L-\delta \sigma K_{r}\right) \\
U_{4}^{m}= & U_{3}^{m}=E\left(\pi^{m}\right)-K_{m} \sqrt{\operatorname{Var}\left(\pi^{m}\right)}=\left(W e^{-\gamma M}-C-W M I\right)\left(\delta a+b_{1} N-\theta L-\delta \sigma K_{m}\right) \\
& +\left(W e^{-\gamma L}-C-P L I\right)\left[(1-\delta) a+b_{2} L-\theta N-(1-\delta) \sigma K_{m}\right] .
\end{aligned}
$$

Solving equations (5.13) and (5.14) by the backward induction method. The following result are obtained.

Proposition 5.9. When both actors have risk preferences, the optimal delayed payment periods are given by

$$
\begin{aligned}
L_{4}= & \frac{\left(2 b_{1} b_{2}-\theta-b_{1} \theta\right)(W-C)+b_{1} \theta W M(\gamma+I)}{(W \gamma+P I)\left(4 b_{1} b_{2}-2 \theta^{2}\right)}+\frac{-2 b_{1}(a-\delta a)}{4 b_{1} b_{2}-2 \theta^{2}} \\
& -\frac{\left(\delta a \theta-\delta \sigma \theta K_{r}\right) P(\gamma+I)+b_{1} \theta(P-W+W M I)-2 b_{1}(1-\delta) \sigma K_{m} P(\gamma+I)}{4 b_{1} b_{2} P(\gamma+I)-2 P \theta^{2}(\gamma+I)} \\
N_{4}= & \frac{\delta \sigma K_{r}-\delta a}{2 b_{1}}+\frac{P-W+W M I}{2 P(\gamma+I)}+\frac{\left(2 b_{1} b_{2}-\theta-b_{1} \theta\right)(W-C)+b_{1} \theta W M(\gamma+I)}{2 b_{1}(W d+P I)\left(4 b_{1} b_{2}-2 \theta^{2}\right)} \\
& -\frac{2 b_{1}(a-\delta a)}{4 b_{1} b_{2}-2 \theta^{2}}-\frac{\left(\delta a \theta-\delta \sigma \theta K_{r}\right)}{8 b_{1}^{2} b_{2}-4 b_{1} \theta^{2}}-\frac{b_{1} \theta(P-W+W M I)-2 b_{1}(1-\delta) \sigma K_{m} P(\gamma+I)}{8 b_{1}^{2} b_{2} P(\gamma+I)-4 b_{1} P \theta^{2}(\gamma+I)} .
\end{aligned}
$$

If $N_{4} \geq 0, N_{4}^{*}=N_{4}$ as shown in equation (5.16); otherwise, $N_{4}^{*}=0$. Similarly, if $L_{4} \geq 0, L_{4}^{*}=L_{4}$, else, $L_{4}^{*}=0$. The explanation of Proposition 5.9 is similar to that of Proposition 5.1.

From Proposition 5.9, we can get Corollary 5.10: 
TABLE 2. Optimal forms of decision variables for various decision instances.

\begin{tabular}{lll}
\hline \hline Model & Delayed payment period $N_{i}^{*}$ & Delayed payment period $L_{i}^{*}$ \\
\hline$i=1$ & $N_{1}^{*}$ & $L_{1}^{*}$ \\
$i=2$ & $N_{1}^{*}+\frac{\delta \sigma \theta K_{r}+\delta \sigma K_{r}\left(4 b_{1} b_{2}-2 \theta^{2}\right)}{2 b_{1}\left(4 b_{1} b_{2}-2 \theta^{2}\right)}$ & $L_{1}^{*}+\frac{\delta \sigma \theta K_{r}}{4 b_{1} b_{2}-2 \theta^{2}}$ \\
$i=3$ & $N_{1}^{*}+\frac{(1-\delta) \sigma K_{m}}{4 b_{1} b_{2}-2 \theta^{2}}$ & $L_{1}^{*}+\frac{2 b_{1}(1-\delta) \sigma K_{m}}{4 b_{1} b_{2}-2 \theta^{2}}$ \\
$i=4$ & $N_{1}^{*}+\frac{\delta \sigma \theta K_{r}+\delta \sigma K_{r}\left(4 b_{1} b_{2}-2 \theta^{2}\right)}{2 b_{1}\left(4 b_{1} b_{2}-2 \theta^{2}\right)}+\frac{(1-\delta) \sigma K_{m}}{4 b_{1} b_{2}-2 \theta^{2}}$ & $L_{1}^{*}+\frac{\delta \sigma \theta K_{r}}{4 b_{1} b_{2}-2 \theta^{2}}+\frac{2 b_{1}(1-\delta) \sigma K_{m}}{4 b_{1} b_{2}-2 \theta^{2}}$ \\
\hline
\end{tabular}

\section{Corollary 5.10.}

(1) $L_{4}^{*}>L_{1}^{*}$.

(2) $N_{4}^{*}>N_{1}^{*}$.

(3) $\frac{\mathrm{d} L_{4}^{*}}{\mathrm{~d} K_{m}}>0, \frac{\mathrm{d} L_{4}^{*}}{\mathrm{~d} K_{r}}>0, \frac{\mathrm{d} N_{4}^{*}}{\mathrm{~d} K_{m}}>0, \frac{\mathrm{d} N_{4}^{*}}{\mathrm{~d} K_{r}}>0$.

Therefore, when both actors have risk preferences, the retailer and manufacturer determine the optimal solutions through game competition, and the optimal actors' utility are $U_{4}^{r^{*}}\left(N_{4}^{*}, L_{4}^{*}\right)$ and $U_{4}^{m^{*}}\left(N_{4}^{*}, L_{4}^{*}\right)$ respectively. Corollary 5.11 can be deduced as follows:

Corollary 5.11. Under the condition $\theta>1 / 2$

(1) $\frac{\mathrm{d} U_{4}^{m^{*}}}{\mathrm{~d} K_{m}}<0$

(2) $\frac{\mathrm{d} U_{4}^{r^{*}}}{\mathrm{~d} K_{m}}<0, \frac{\mathrm{d} U_{4}^{r^{*}}}{\mathrm{~d} K_{r}}<0, U_{4}^{r^{*}}<U_{1}^{r^{*}}$.

Corollaries 5.10 and 5.11 suggest that when both actors have a risk preference, they will provide a longer delayed payment period to the customers for increasing customers demand. Moreover, the delayed payment period increases as risk aversion coefficient, while the retailer's utility will decrease. Compared with the risk neutral retailer and manufacturer, the manufacturer's utility will decrease as its own risk aversion coefficient. As the manufacturer is dominated, a higher risk aversion coefficient will cause a lower utility for the manufacturer. The retailer benefits from reduced risk aversion coefficient. To facilitate analysis, the optimal terms of the decision variables are summarized in the four decision instances in Table 2, using the same notation for the subscript $i$.

The following corollaries can be obtained:

\section{Corollary 5.12.}

(1) If $\delta<\frac{2 U_{1} \Lambda_{m}}{\left(4 b_{1} b_{2}-2 \theta^{2}\right) K_{r}+2 b_{1} K_{m}}$, then $N_{4}^{*}>N_{3}^{*}>N_{2}^{*}>N_{1}^{*}>0$.

(2) If $\delta>\frac{2 b_{1} K_{m}}{\left(4 b_{1} b_{2}-2 \theta^{2}\right) K_{r}+2 b_{1} K_{m}}$, then $N_{4}^{*}>N_{2}^{*}>N_{3}^{*}>N_{1}^{*}>0$.

(3) If $\delta=\frac{2 b_{1} K_{m}}{\left(4 b_{1} b_{2}-2 \theta^{2}\right) K_{r}+2 b_{1} K_{m}}$, then $N_{4}^{*}>N_{2}^{*}=N_{3}^{*}>N_{1}^{*}>0$.

\section{Corollary 5.13.}

(1) If $\delta<\frac{2 b_{1} K_{m}}{\theta K_{r}+2 b_{1} K_{m}}$, then $L_{4}^{*}>L_{3}^{*}>L_{2}^{*}>L_{1}^{*}>0$. 
(2) If $\delta>\frac{2 b_{1} K_{m}}{\theta K_{r}+2 b_{1} K_{m}}$, then $L_{4}^{*}>L_{2}^{*}>L_{3}^{*}>L_{1}^{*}>0$.

(3) If $\delta=\frac{2 b_{1} K_{m}}{\theta K_{r}+2 b_{1} K_{m}}$, then $L_{4}^{*}>L_{2}^{*}=L_{3}^{*}>L_{1}^{*}>0$.

Corollaries 5.12 and 5.13 show that when both actors have risk preferences, either of them offers the longest delayed payment period to the customers to control the risk and increase demand. When the retailer or the manufacturer has a risk preference, the delayed payment period will longer than the one that both actors are risk neutral. It can be seen that if the market share of the retail channel is less than a certain value, the delayed payment period of only have a risk preferred manufacturer is longer than of only have a risk preferred retailer. Low market share means that the manufacturer has large basic demand in the network channel. In such circumstance, the manufacturer's risk preference plays an important role in the decision of delayed payment periods.

\section{Delayed Payment inCEntive CONTRACT}

So far, we note that when only the manufacturer has a risk preference, the utility of the manufacturer and retailer are reduced. When both actors have risk preferences, the retailer's utility decreases but the manufacturer's utility is uncertain. Therefore, the coordination in these two decision instances has not been considered. Specifically, when only the retailer has a risk preference, the retailer's utility decreases due to risk aversion, while the manufacturer's utility will increase due to more demand of the traditional retail channel. Therefore, the retailer is more willing to accept coordination to obtain greater utility. Now, we formulate a delayed payment incentive between the manufacturer and retailer to realize coordination.

The delayed payment period by the manufacturer to retailer can be changed, thus the utility of the manufacturer and retailer will be also. Suppose the manufacturer changes the delayed payment period available to the retailer, that is $\beta M(\beta>0)$, the manufacturer and the retailer are encouraged to accept the contract. The respective actors' utility can be expressed as:

$$
\begin{aligned}
U_{o}^{r}= & E\left(\pi_{o}^{r}\right)-K_{r} \sqrt{\operatorname{Var}\left(\pi_{o}^{r}\right)}=\left(P e^{-\gamma N}+\beta W M I-W-P N I\right)\left(\delta a+b_{1} N-\theta L-\delta \sigma K_{r}\right) \\
U_{o}^{m}= & E\left(\pi_{o}^{m}\right)=\left(W e^{-\beta \gamma M}-C-\beta W M I\right)\left(\delta a+b_{1} N-\theta L\right) \\
& +\left(W e^{-\gamma L}-C-P L I\right)\left[(1-\delta) a+b_{2} L-\theta N\right] .
\end{aligned}
$$

Solving equations (6.1) and (6.2) by the backward induction method. The following result are obtained.

Proposition 6.1. Under a delayed payment incentive contract, the optimal delayed payment periods are given by

$$
\begin{aligned}
L_{o}= & \frac{\left(2 b_{1} b_{2}-\theta-b_{1} \theta\right)(W-C)+\beta b_{1} \theta W M(\gamma+I)}{(W \gamma+P I)\left(4 b_{1} b_{2}-2 \theta^{2}\right)}-\frac{2 b_{1}(a-\delta a)}{4 b_{1} b_{2}-2 \theta^{2}} \\
& +\frac{\left(\delta a \theta-\delta \sigma \theta K_{r}\right) P(\gamma+I)+b_{1} \theta(P-W+\beta W M I)}{4 b_{1} b_{2} P(\gamma+I)-2 P \theta^{2}(\gamma+I)} \\
N_{o}= & \frac{P-W+\beta W M I}{2 P(\gamma+I)}+\frac{\left(2 b_{1} b_{2}-\theta-b_{1} \theta\right)(W-C)+\beta b_{1} \theta W M(\gamma+I)}{2 b_{1}(W \gamma+P I)\left(4 b_{1} b_{2}-2 \theta^{2}\right)}+\frac{\delta \sigma K_{r}-\delta a}{2 b_{1}} \\
& -\frac{2 b_{1} P(a-\delta a)(\gamma+I)+\left(\delta a \theta-\delta \sigma \theta K_{r}\right) P(\gamma+I)+b_{1} \theta(P-W+\beta W M I)}{8 b_{1}^{2} b_{2} P(\gamma+I)-4 b_{1} P \theta^{2}(\gamma+I)} .
\end{aligned}
$$

If $N_{o} \geq 0, N_{o}^{*}=N_{o}$ as shown in equation (6.4); otherwise, $N_{o}^{*}=0$. Similarly, if $L_{o} \geq 0, L_{o}^{*}=L_{o}$, else, $L_{o}^{*}=0$. The explanation of Proposition 6.1 is similar to that of Proposition 5.1.

To achieve coordination, the total utility upon coordination will not be lower than that before coordination. That is, we must have $U_{o}^{r^{*}}+U_{o}^{m^{*}} \geq U_{2}^{r^{*}}+U_{2}^{m^{*}}$. Substituting equations (6.1) and (6.2) into the condition, we 
get

$$
\begin{aligned}
& \left(P e^{-\gamma N_{0}^{*}}+\beta W M I-W-P N_{0}^{*} I\right)\left(\delta a+b_{1} N_{0}^{*}-\theta L_{0}^{*}-\delta \sigma K_{r}\right)+\left(W e^{-\gamma \beta M}-C-\beta W M I\right) \\
& \left(\delta a+b_{1} N_{0}^{*}-\theta L_{0}^{*}\right)+\left(W e^{-\gamma L_{0}^{*}}-C-P L_{0}^{*} I\right)\left[(1-\delta) a+b_{2} L_{0}^{*}-\theta N_{0}^{*}\right] \geq \\
& \left(P e^{-\gamma N_{2}^{*}}+W M I-W-P N I\right)\left(\delta a+b_{1} N_{2}^{*}-\theta L_{2}^{*}-\delta \sigma K_{r}\right)+\left(W e^{-\gamma M}-C-W M I\right) \\
& \left(\delta a+b_{1} N_{2}^{*}-\theta L_{2}^{*}\right)+\left(W e^{-\gamma L_{2}^{*}}-C-P L_{2}^{*} I\right)\left[(1-\delta) a+b_{2} L_{2}^{*}-\theta N_{2}^{*}\right] .
\end{aligned}
$$

Corollary 6.2. When $0 \geq \beta \leq \bar{\beta}$, this coordination mechanism is effective and can increase the total utility. In particular,

$$
\bar{\beta}=\frac{\left\{\begin{array}{l}
\left(P e^{-\gamma N_{2}^{*}}+W M I-W-P N_{2}^{*} I\right)\left(\delta a+b_{1} N_{2}^{*}-\theta L_{2}^{*}-\delta \sigma K_{r}\right) \\
+\left(W e^{-\gamma M_{2}^{*}}-C-W M_{2}^{*} I\right)\left(\delta a+b_{1} N_{2}^{*}-\theta L_{2}^{*}\right)+\left(W e^{-\gamma L_{2}^{*}}-C-P L_{2}^{*} I\right) \\
{\left[(1-\delta) a+b_{2} L_{2}^{*}-\theta N_{2}^{*}\right]-\left(W e^{-\gamma L_{0}^{*}}-C-P L_{0}^{*} I\right)\left[(1-\delta) a+b_{2} L_{0}^{*}-\theta N_{0}^{*}\right]} \\
-\left(P e^{-\gamma N_{0}^{*}}-W-P N_{0}^{*} I\right)\left(\delta a+b_{1} N_{0}^{*}-\theta L_{0}^{*}-\delta \sigma K_{r}\right) \\
+(W-C)\left(\delta a+b_{1} N_{0}^{*}-\theta L_{0}^{*}\right)
\end{array}\right\}}{\left(\mathrm{d} \delta a+\mathrm{d} b_{1} N_{0}^{*}\right) W M-\left(\mathrm{d} \theta L_{0}^{*}+I \delta \sigma K_{r}\right) W M} .
$$

As indicated in Corollary 6.2, when the incentive coefficient of the delayed payment satisfies the condition, the supply chain can be effectively coordinated, that is, $U_{o}^{r^{*}}+U_{o}^{m^{*}} \geq U_{2}^{r^{*}}+U_{2}^{m^{*}}$, implying that the incentive contract can effectively work considering the retailer's risk preference. Therefore, the validity of incentive contract can be evaluated by Corollary 6.2 .

\section{NUMERICAL EXPERIMENTATION}

Numerical examples are given to verify the theoretical results. Figures 2-6 summarize the results of the numerical examples. We follow the numerical value adopted in Huang and Swaminathan [26] and Teng et al. [49] with $c=\$ 1 /$ unit, $W=\$ 3 /$ unit, $P=\$ 5 /$ unit, $\gamma=0.1, M=0.5, \theta=3, b_{1}=b_{2}=40, r=\$ 0.1 /$ unit/year, $\delta=0.6, a=100, \sigma=10$.

With $K_{r}=K_{m}=0$, optimality occurs when $U_{1}^{*}=0.333$ and $L_{1}^{*}=0.6424$. The optimal utility of the retailer and manufacturer is given as $U_{1}^{r^{*}}=\$ 129.721, U_{1}^{m^{*}}=\$ 217.5144$. Next, we analysis how the risk preference coefficient affects the optimal delayed payment periods and the utility of the retailer and manufacturer, to ascertain that the coordination contract can achieve effective coordination certain extent to maximize the total utility.

\subsection{Influence of retailer's risk aversion coefficient}

Figure 2 shows the impact of $K_{r}$ on $N_{2}^{*}, L_{2}^{*}, U_{2}^{r^{*}}$ and $U_{2}^{m^{*}}$, against the decision instance when both the manufacturer and retailer are risk neutral.

From Figures 2a and 2b, compared with the instance of actors are risk neutral, in the case of only the retailer has a risk preference, both actors will increase the delayed payment periods to the customers to increase demand and resist risk. As the delayed payment periods $N_{2}^{*}$ and $L_{2}^{*}$ increase when $K_{r}$ increases, compared to a risk neutral retailer and manufacturer, the increase in the delayed payment period that the retailer gives to the customers is longer than that the manufacturer gives to the customers, which supports Corollary 5.3.

Thus, a higher value of $K_{r}$ leads to a lower retailer's utility while a higher manufacturer's utility provided that only the retailer has a risk preference as shown in Figures 2c and 2d. By comparing with the instance that both actors are risk neutral, the utility of the retailer decreases while the utility of manufacturer increase. Moreover, from Figures 2c and 2d, the decrease in the retailer's utility outweighs that the increase in the manufacturer's utility. Therefore, the total utility decreases as the risk preference coefficient increases and the total utility is lower than when actors are risk neutral, which supports Corollary 5.4. Hence, the retailer's risk preference is unfavorable to the retailer but beneficial to the manufacturer. 


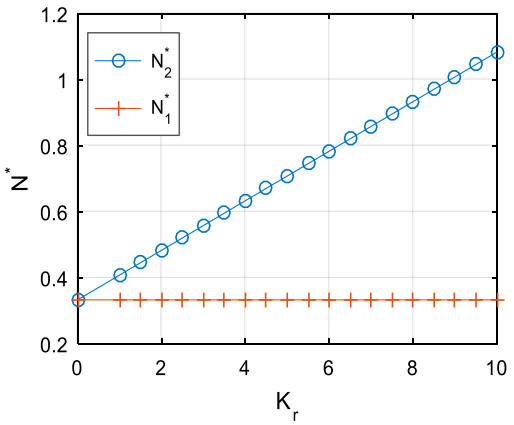

(a)

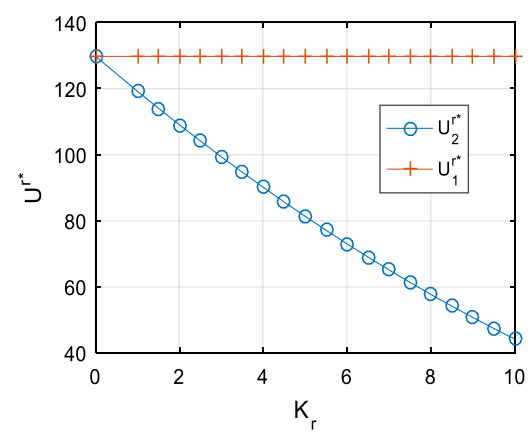

(c)

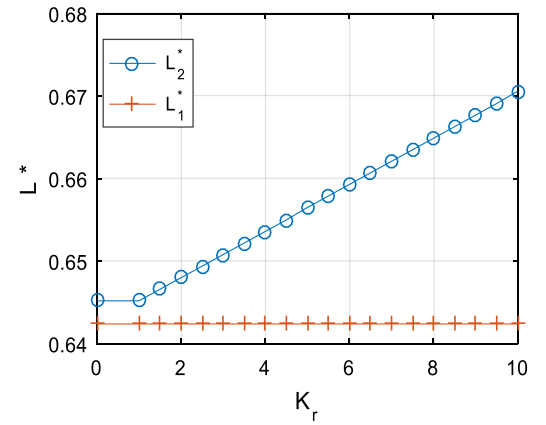

(b)

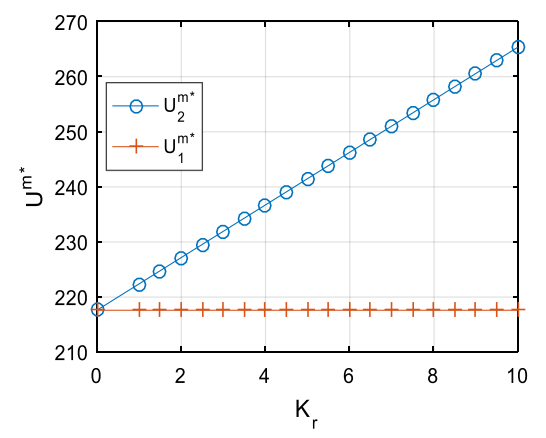

(d)

FIGURE 2. Effect of $K_{r}$ on decision variables and utility.

Thus, when the retailer and the manufacturer provide delayed payment periods to increase the demand, the retailer should accept a lower risk aversion coefficient to increase the total supply chain utility.

\subsection{Influence of manufacturer's risk aversion coefficient}

Figure 3 shows the impact of $K_{m}$ on $N_{3}^{*}, L_{3}^{*}, U_{3}^{r^{*}}$ and $U_{3}^{m^{*}}$, compared to when actors both are risk neutral.

From Figures $3 \mathrm{a}$ and $3 \mathrm{~b}$, when only the manufacturer has a risk preference, compared against when both actors are risk neutral, the manufacturer and retailer will increase the delayed payment periods to their customers for increasing demand and mitigating risk. The delayed payment periods $N_{3}^{*}$ and $L_{3}^{*}$ increase when $K_{m}$ increases. Compared to the risk neutral retailer and manufacturer, the increase in the delayed payment period that the manufacturer gives to the customers is longer than that given to the customers by the retailer, supporting Corollary 5.6.

Thus, a higher $K_{m}$ will lead to the reduction of the retailer's utility and manufacturer's utility provided that only the manufacturer has a risk preference as shown in Figures $3 \mathrm{c}$ and $3 \mathrm{~d}$. Under this circumstance, the retailer's utility is lower than that both actors are risk neutral. The same applies for the manufacturer's utility. Moreover, the total utility decreases when the risk preference coefficient increases, and the total utility is lower, compared with case that both actors are risk neutral, which supports Corollary 5.7. Hence, the manufacturer's risk preference does not benefit actors' utility.

As the risk aversion of the manufacturer is unfavorable to the actors' utility, the manufacturer should lower his risk aversion coefficient to lift the total utility. 


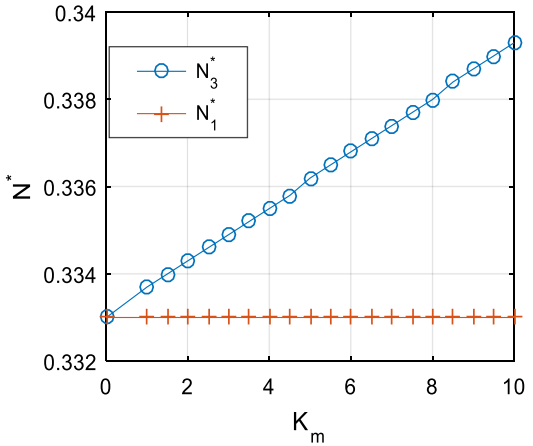

(a)

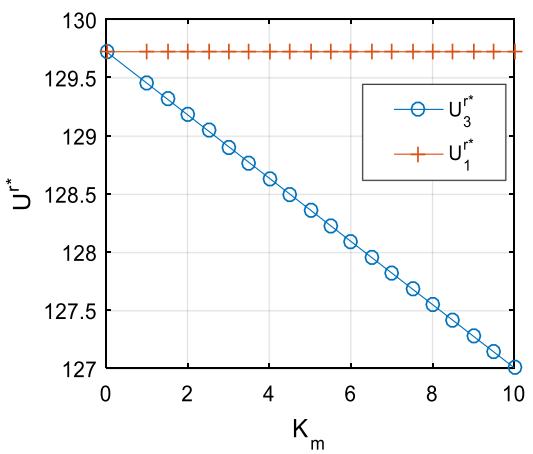

(c)

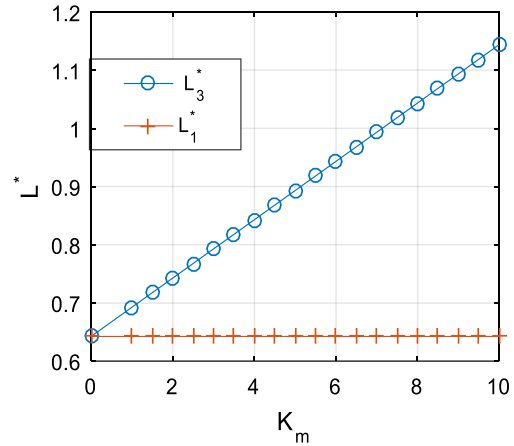

(b)

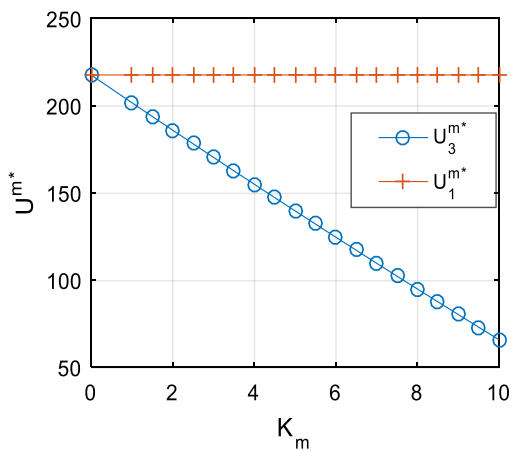

(d)

Figure 3 . Effect of $K_{m}$ on decision variables and utility

TABLE 3 . Effect of $K_{r}$ and $K_{m}$ on decision variables and utility.

\begin{tabular}{lllllll}
\hline \hline$K_{r}$ & $K_{m}$ & $L_{4}^{*}$ & $N_{4}^{*}$ & $U_{4}^{r^{*}}$ & $U_{4}^{m^{*}}$ & $U_{4}^{s c^{*}}$ \\
\hline 0 & 0 & 0.6424 & 0.333 & 129.721 & 217.5144 & 347.2354 \\
1 & 1 & 0.6953 & 0.4087 & 118.8647 & 206.4041 & 325.2688 \\
2 & 2 & 0.7483 & 0.4844 & 108.4824 & 195.4724 & 303.9548 \\
3 & 3 & 0.8012 & 0.5600 & 98.5741 & 184.7194 & 283.2935 \\
4 & 4 & 0.8542 & 0.6357 & 89.1398 & 174.1451 & 263.2849 \\
5 & 5 & 0.9072 & 0.7113 & 80.1796 & 163.7494 & 243.929 \\
6 & 6 & 0.9601 & 0.7870 & 71.6933 & 153.5325 & 225.2258 \\
2 & 1 & 0.6981 & 0.4837 & 108.7321 & 211.1890 & 319.9211 \\
1 & 2 & 0.7455 & 0.4093 & 118.6037 & 190.6785 & 309.2822 \\
3 & 4 & 0.8514 & 0.5606 & 98.3360 & 169.3321 & 267.6681 \\
4 & 3 & 0.8041 & 0.6351 & 89.3666 & 189.5234 & 278.8900 \\
\hline
\end{tabular}

\subsection{Influence of manufacturer's and retailer's risk aversion coefficient}

Table 3 shows the effects of the actors' risk aversion coefficient $K_{m}$ and $K_{r}$ on $N_{4}^{*}, L_{4}^{*}, U_{4}^{r^{*}}, U_{4}^{m^{*}}$ and $U_{4}^{s c^{*}}$, compared to when actors both are risk neutral.

Table 3 suggests that if both actors have risk preferences and $K_{r}$ and $K_{m}$ is higher, the delayed payment periods, that the manufacturer and retailer offer to the customers, will increase. In addition, the actors' utility 

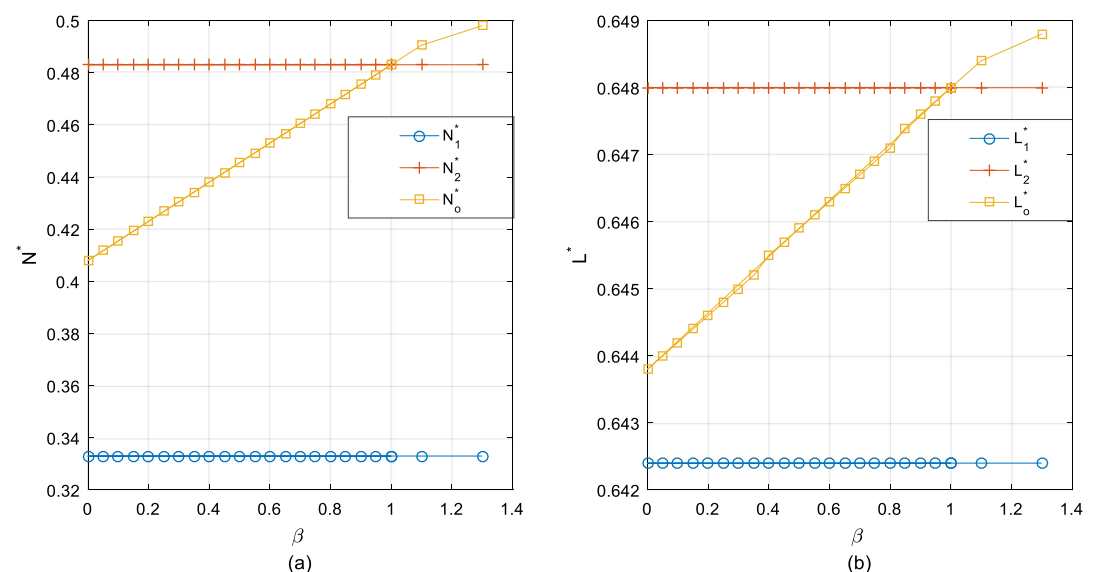

FiguRE 4. Effect of $\beta$ on $L^{*}$ and $N^{*}$.

decrease as $K_{r}$ and $K_{m}$. Therefore, the total utility decreases as $K_{r}$ and $K_{m}$. Hence, the manufacturer and retailer should reduce their risk aversion coefficients and increase their capacity to bear more risk in order to obtain greater utility.

When $K_{r}$ decreases and $K_{m}$ increases, the delayed payment period that the retailer gives to the customers will decrease while the delayed payment period that the manufacturer gives to the customers increase. Under this circumstance, the retailer's utility increases while the manufacturer's utility decreases. As a result, the total utility decreases. Therefore, $K_{r}$ has a greater effect on the delayed payment period that the retailer gives to the customers and on the utility of the retailer.

When $K_{m}$ decreases and $K_{r}$ increases, the delayed payment period that the retailer gives to the customers will increase, while the delayed payment period that the manufacturer gives to the customers decrease. Under this circumstance, the retailer's utility decreases while the manufacturer's utility increases. As a result, the total utility increases. Thus, $K_{m}$ has a greater effect on the delayed payment periods by the manufacturer to customers, and on the actors' utility.

In short, the total utility can be significantly impacted by the risk aversion coefficient. The total utility decreases with the increase of risk aversion coefficient. Therefore, the supply chain actors should reduce the risk aversion coefficient and increase the capacity for absorbing risk to obtain more utility. The manufacturer should reduce the risk aversion coefficient to increase the total utility.

\subsection{Influence of delayed payment incentive coefficient}

From Figures $4 \mathrm{a}$ and $4 \mathrm{~b}$, when the manufacturer reduces the delayed payment periods to the retailer $(0 \geq \beta \leq 1)$, the optimal delayed payment periods that the manufacturer and retailer offer to the customers are longer than those when actors are risk neutral, but shorter than those when the retailer has a risk preference. When the manufacturer increases the delayed payment periods to the retailer $(\beta>1)$, the optimal delayed payment periods that the manufacturer and retailer give to the customers are longest than those under the condition of actors are risk neutral or only the retailer has a risk preference. Thus, when the manufacturer extends the delayed payment periods to the retailer, actors will also extend the delayed payment periods to the customers.

From Figure 5a, the retailer's utility with coordination is less than that before coordination and lower than that when actors are risk neutral, indicating that the retailer cannot benefit from coordination with $0 \geq \beta \leq 1$. However, when $\beta>1$, the retailer's utility after coordination will be greater, albeit still lower than that when actors are risk neutral. The larger $\beta$ is, the longer the delayed payment period by the manufacturer to retailer 

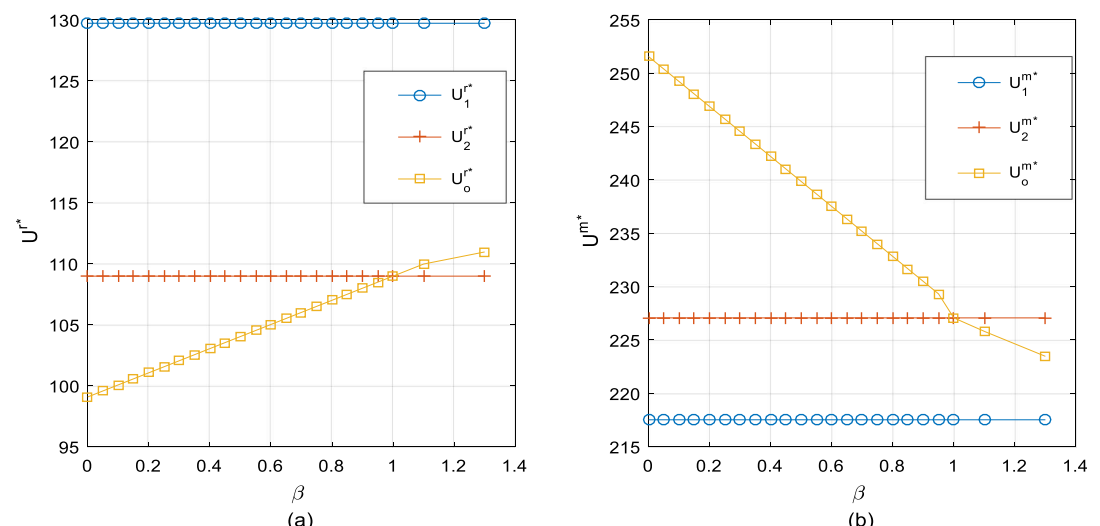

(a)

Figure 5. Effect of $\beta$ on utility.

will be, which will be more beneficial to the retailer. That is, the retailer's utility increases as $\beta$. Hence, the retailer wants the manufacturer to provide longer delayed payment period.

Further, the manufacturer can obtain a higher utility from the contract when $0 \geq \beta \leq 1$, and it also be greater than those under risk neutrality in Figure 5b. However, when $\beta>1$, the manufacturer's utility before coordination is the highest. In other words, the larger $\beta$ is, the longer the delayed payment period by the manufacturer to retailer, which will be more unfavorable to the manufacturer. Thus, the manufacturer should seek to provide shorter delayed payment period to the retailer, which conflicts with the retailer's strategy mentioned above.

Figure 6 describes the impact of $\beta$ on the total utility. When $\beta$ is in a certain range, the total utility is greater than that when the manufacturer and retailer are risk neutral or only the retailer has a risk preference. In addition, at the intersection of the two lines between $U_{1}^{s c^{*}}$ and $U_{o}^{s c^{*}}$ is the threshold value of $\beta$. If $0 \leq \beta \leq \underline{\beta}$, the coordination mechanism can lead to the total utility after coordination being larger than that when actors are risk neutral. Therefore, the proposed contract can achieve effective coordination and increase the total utility. At the intersection of the two lines between $U_{2}^{s c^{*}}$ and $U_{o}^{s c^{*}}$ is the threshold $\bar{\beta}$. When $\underline{\beta} \leq \beta \leq \bar{\beta}$, the coordination mechanism can result in the total utility after coordination being greater than the total utility when the retailer has a risk preference but lower than that when actors are risk neutral. Hence, the mechanism can achieve coordination.

In sum, when the manufacturer shortens the delayed payment periods to the retailer, the retailer's utility decreases but the manufacturer's utility increases together with the utility of the entire supply chain. When the total utility is larger when only the retailer has a risk preference, that is, $0 \leq \beta \leq \beta$, the manufacturer can make the retailer willing to accept the contract by transferring a fixed cost to the retailer to achieve win-win situation. Therefore, the contract can facilitate a win-win scenario when $0 \leq \beta \leq \underline{\beta}$, which supports Corollary 5.10.

\section{Conclusion}

The paper introduces the risk preference to the dual-channel supply chain to analyze the decision problem of delayed payment periods. How the risk preference coefficient affects the decisions and utility of the actors are analyzed and verified numerically. By comparing the utility of the four decision instances, the study proposes an incentive mechanism for the delayed payment periods that the manufacturer should offer to the retailer. Technically, when the contract parameter is range bound, the contract can achieve coordination and maximize the total utility.

This paper makes the following contributions in dual-channel supply chain management and coordination field. First, we study the correlation between risk preference and delay payment period. We found that the 


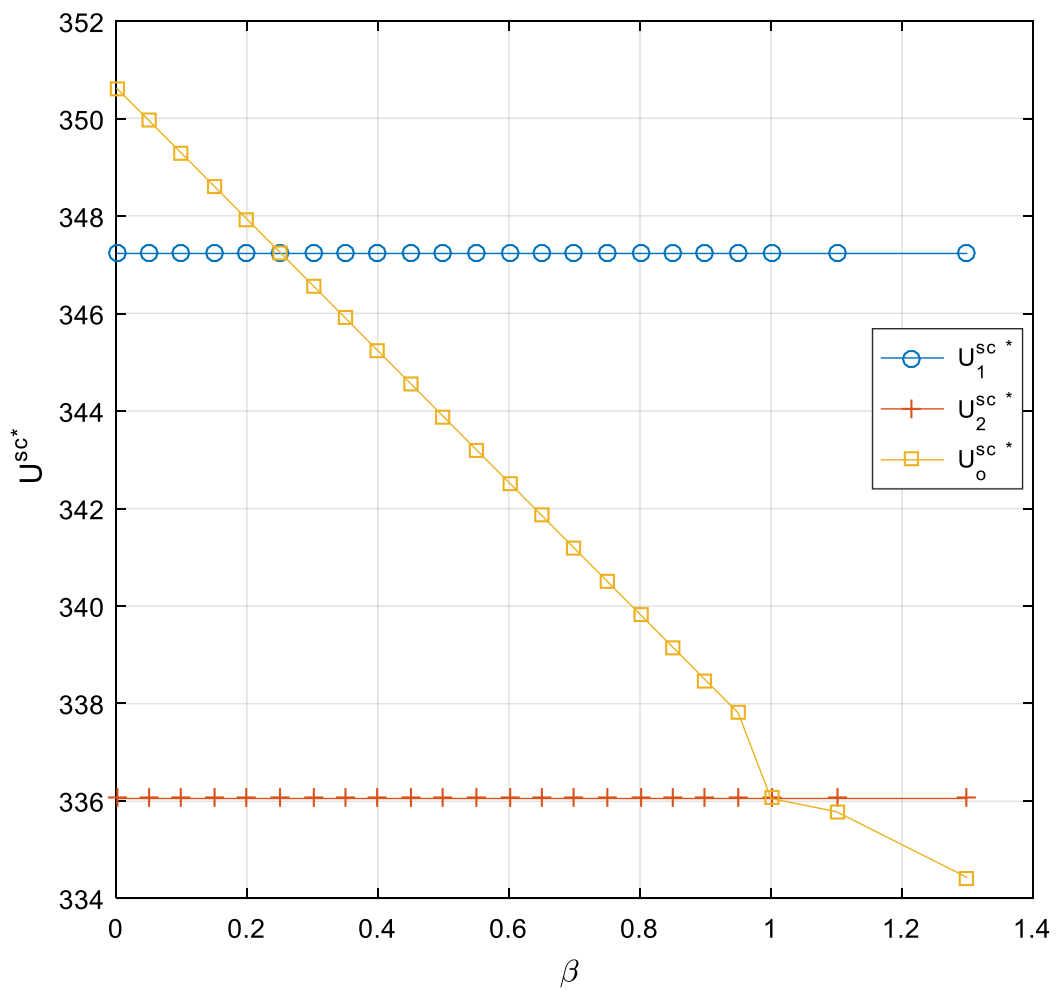

(a)

FIGURE 6 . Effect of $\beta$ on utility of overall supply chain.

length of delayed payment period increases as risk aversion of the manufacturer and the retailer. Therefore, the delayed payment periods of risk-neutral supply chain are shorter. Secondly, the degree of risk aversion affects the supply chain performance. The higher the risk aversion of the actors, the lower the utility of the whole supply chain. Finally, we developed a new coordination contract related to delay payment period, and results showed the contract can achieve coordination when the contract coefficient is within a certain range. As far as we know, there is no research on delayed payment incentive contract in the previous literature.

The above observations can also provide some theoretical guidance for decision makers to make operational decisions on improving dual-channel supply chain performance. Leading manufacturers should consider their own risk attitude when developing direct channels to determine the delay payment period for customers. A moderate delay payment period can not only increase the demand for the direct channel, but also avoid higher risks to a certain extent. At the same time, the manufacturer should increase its risk tolerance to obtain a higher utility. When the manufacturer chooses a retailer for offline sales, the degree of risk aversion of retailers should be investigated. The higher the degree of risk aversion, the lower the utility of the manufacturer. Therefore, the manufacturer should choose a retailer that are more risk tolerant, i.e. with low risk aversion coefficient, to cooperate. Finally, the manufacturer can appropriately reduce the delay payment period given to the retailer to increase the total utility. At the same time, payment transfer and other contracts can also be combined with delayed payment incentive contract to achieve a win-win situation.

There are some other directions worth studying. For example, we consider a monopolistic manufacturer and an exclusive retailer under the dual-channel environment. What happens if there is competition between multiple manufacturers and multiple retailers? Besides, if the exact demand information is private information of the retailer, how does asymmetric information affect the supply chain performance? Furthermore, do customers in 
different market segments have different acceptance of two channels? If so, how and why? We will consider these questions in the future work.

\section{Appendix A.}

\section{Description of the demand functions}

We consider that the demand function consists of two deterministic decision variables and a random variable. Among them, the two deterministic decision variables are the delayed payment periods provided by actors to the end customer. In a certain environment, the promised delay period attracts new buyers, who may think this is a way to cut prices. Therefore, from the seller's perspective, the delay period can increase sales. In fact, there are generally three simple ways to express the demand function as the credit period increases: linear, polynomial or exponential (see [49]). Therefore, we use a linear demand function to analyze the decision-making behavior of decision makers (see [46]). That is

$$
\begin{aligned}
D_{r} & =\delta \widetilde{a}+b_{1} N-\theta_{1} L \\
D_{d} & =(1-\delta) \widetilde{a}+b_{2} L-\theta_{2} N .
\end{aligned}
$$

The related parameter explanation can refer to the problem description. In the demand functions, we do not consider the influence of price on demand. This is because we illustrated the case and background of the online and offline price consistency. That is, the prices of both channels are consistent. Therefore, there is no competition between prices, and the demand is mainly affected by the trade credit period. Therefore, the influence of price on demand can be ignored, and the paper assumes that the demand function is only related to the trade credit period.

Apart from the deterministic decision variables mentioned above, we also include randomness indicators and functions (see [4]). $\widetilde{a}(>0)$ is the basic market demand and $\widetilde{a}=a+\xi$, where $a$ denotes the identified market demand and $\xi$ is a random factor with $E(\xi)=0$ and $\operatorname{Var}(\xi)=\sigma^{2}$ for measuring the uncertainty of market demand. Thus, we can easily obtain that:

$$
\begin{array}{ll}
E\left(D_{r}\right)=\delta a+b_{1} N-\theta_{1} L ; & \operatorname{Var}\left(D_{r}\right)=\sigma^{2} \\
E\left(D_{d}\right)=(1-\delta) a+b_{2} L-\theta_{2} N ; & \operatorname{Var}\left(D_{d}\right)=\sigma^{2} .
\end{array}
$$

Proof of Proposition 5.1. To simplify the calculation, Taylor's expansion is adopted. Taking the first and second derivatives of $U_{1}^{r}$ w.r.t. $N$, yields $\frac{\mathrm{d} U_{1}^{r}}{\mathrm{~d} N}=-2 b_{1} P N(\gamma+I)-P(\gamma+I)(\delta a-\theta L)+b_{1}(P-W+W M I)$.

$$
\text { As } \frac{\mathrm{d}^{2} U_{1}^{r}}{\mathrm{~d} N^{2}}=-2 b P(\gamma+I)<0 \text {, so } U_{1}^{r} \text { is concave in } N \text {. Let } \frac{\mathrm{d} U_{1}^{r}}{\mathrm{~d} N}=0 \text {, we can get } N_{1}=\frac{\theta L-\delta a}{2 b_{1}}+
$$

$\frac{P-W+W M I}{2 P(\gamma+I)}$. Putting $N_{1}$ into equation (5.2), and taking the first and second derivatives of $U_{1}^{m}$ w.r.t. $L$, yields

$$
\begin{aligned}
\frac{\mathrm{d} U_{1}^{m}}{\mathrm{~d} L}= & \left(b_{2}-\frac{\theta}{2 b_{1}}-\frac{\theta}{2}\right)(W-C)+\frac{\theta}{2} W M(\gamma+I) \\
& -(W \gamma+P I)\left[a-\delta a+\frac{\delta a \theta}{2 b_{1}}+\frac{\theta(P-W+W M I)}{2 P(\gamma+I)}\right]-(W \gamma+P I)\left(2 b_{2}-\frac{\theta^{2}}{b_{1}}\right) L .
\end{aligned}
$$

Assuming that $b_{1}, b_{2}>\theta, \frac{\mathrm{d}^{2} U_{1}^{m}}{\mathrm{~d} L^{2}}=-2(W \gamma+P I)\left(b_{2}-\frac{\theta^{2}}{2 b_{1}}\right)<0$, let $\frac{\mathrm{d} U_{1}^{m}}{\mathrm{~d} L}=0$ and putting $L_{1}$ into $N_{1}$, gives us 


$$
\begin{aligned}
L_{1}= & \frac{\left(2 b_{1} b_{2}-\theta-b_{1} \theta\right)(W-C)+b_{1} \theta W M(\gamma+I)}{(W \gamma+P I)\left(4 b_{1} b_{2}-2 \theta^{2}\right)} \\
& -\frac{2 b_{1} P(a-\delta a)(\gamma+I)+\delta a \theta P(\gamma+I)+b_{1} \theta(P-W+W M I)}{4 b_{1} b_{2} P(\gamma+I)-2 P \theta^{2}(\gamma+I)} \\
N_{1}= & \frac{-\delta a}{2 b_{1}}+\frac{P-W+W M I}{2 P(\gamma+I)}+\frac{\left(2 b_{1} b_{2}-\theta-b_{1} \theta\right)(W-C)+b_{1} \theta W M(\gamma+I)}{2 b_{1}(W \gamma+P I)\left(4 b_{1} b_{2}-2 \theta^{2}\right)} \\
& -\frac{2 b_{1} P(a-\delta a)(\gamma+I)+\delta a \theta P(\gamma+I)+b_{1} \theta(P-W+W M I)}{8 b_{1}^{2} b_{2} P(\gamma+I)-4 b_{1} P \theta^{2}(\gamma+I)} .
\end{aligned}
$$

Proof of Corollary 5.2. Corollary 5.2 can be proved by the optimal values of $N_{1}^{*}$ and $L_{1}^{*}$.

Proof of Proposition 5.3. To determine $N$, we take the first and second derivatives of $U_{2}^{r}$ w.rt. $N$, yielding $\frac{\mathrm{d} U_{2}^{r}}{\mathrm{~d} N}=-2 b_{1} P N(\gamma+I)-P(\gamma+I)\left(\delta a-\theta L-\delta \sigma K_{r}\right)+b_{1}(P-W+W M I)$. As $\frac{\mathrm{d}^{2} U_{2}^{r}}{\mathrm{~d} N^{2}}=-2 b_{1} P(\gamma+I)<0$, so $U_{2}^{r}$ is concave in $N$ and make $\frac{\mathrm{d} U_{2}^{r}}{\mathrm{~d} N}=0$. Thus, $N_{2}=\frac{\theta L+\delta \sigma K_{r}-\delta a}{2 b_{1}}+\frac{P-W+W M I}{2 P(\gamma+I)}$. Putting $N_{2}$ into equation (5.6) and taking the first and second derivatives of $U_{2}^{m}$ w.r.t. $L$, we get

$$
\begin{aligned}
\frac{\mathrm{d} U_{2}^{m}}{\mathrm{~d} L}= & \left(b_{2}-\frac{\theta}{2 b_{1}}-\frac{\theta}{2}\right)(W-C)+\frac{\theta}{2} W M(\gamma+I) \\
& -(W \gamma+P I)\left[a-\delta a+\frac{\delta a \theta}{2 b_{1}}+\frac{\theta(P-W+W M I)}{2 P(\gamma+I)}-\frac{\delta \sigma \theta K_{r}}{2 b_{1}}\right] \\
& -(W \gamma+P I)\left(2 b_{2}-\frac{\theta^{2}}{b_{1}}\right) L .
\end{aligned}
$$

Assuming $b_{1}, b_{2}>\theta, \frac{\mathrm{d}^{2} U_{2}^{m}}{\mathrm{~d} L^{2}}=-2(W \gamma+P I)\left(b_{2}-\frac{\theta}{2 b_{1}}\right)<0$, the optimal solution satisfying the condition $\frac{\mathrm{d} U_{2}^{m}}{\mathrm{~d} L}=0$ and taking $L_{2}$ into $N_{2}$, we get

$$
\begin{aligned}
L_{2}= & \frac{\left(2 b_{1} b_{2}-\theta-b_{1} \theta\right)(W-C)+b_{1} \theta W M(\gamma+I)}{(W d+P I)\left(4 b_{1} b_{2}-2 \theta^{2}\right)} \\
& -\frac{2 b_{1} P(a-\delta a)(\gamma+I)+\left(\delta a \theta-\delta \sigma \theta K_{r}\right) P(\gamma+I)+b_{1} \theta(P-W+W M I)}{4 b_{1} b_{2} P(\gamma+I)-2 P \theta^{2}(\gamma+I)} \\
N_{2}= & \frac{\delta \sigma K_{r}-\delta a}{2 b_{1}}+\frac{P-W+W M I}{2 P(\gamma+I)}+\frac{\left(2 b_{1} b_{2}-\theta-b_{1} \theta\right)(W-C)+b_{1} \theta W M(\gamma+I)}{2 b_{1}(W d+P I)\left(4 b_{1} b_{2}-2 \theta^{2}\right)} \\
& -\frac{2 b_{1} P(a-\delta a)(\gamma+I)+\left(\delta a \theta-\delta \sigma \theta K_{r}\right) P(\gamma+I)+b_{1} \theta(P-W+W M I)}{8 b_{1}^{2} b_{2} P(\gamma+I)-4 b_{1} P \theta^{2}(\gamma+I)} .
\end{aligned}
$$

Proof of Corollary 5.4. From the optimal solutions for $N_{2}^{*}$ and $L_{2}^{*}, \quad \frac{\mathrm{d} L_{2}^{*}}{\mathrm{~d} K_{r}}=\frac{\delta \sigma \theta}{\left(4 b_{1} b_{2}-2 \theta^{2}\right)}>0$ is easily obtained. $\frac{\mathrm{d} N_{2}^{*}}{\mathrm{~d} K_{r}}=\frac{\delta \sigma \theta}{2 b_{1}\left(4 b_{1} b_{2}-2 \theta^{2}\right)}+\frac{\delta \sigma}{2 b_{1}}>0$ and $\frac{\mathrm{d} N_{2}^{*}}{\mathrm{~d} K_{r}}-\frac{\mathrm{d} L_{2}^{*}}{\mathrm{~d} K_{r}}=\frac{\delta \sigma\left(\theta+4 b_{1} b_{2}-2 \theta^{2}-2 b_{1} \theta\right)}{2 b_{1}\left(4 b_{1} b_{2}-2 \theta^{2}\right)}>0$, which supports Corollary 5.4. 
Proof of Corollary 5.5. With $U_{2}^{r^{*}}$, we can get

$$
\begin{aligned}
\frac{\mathrm{d} U_{2}^{*}}{\mathrm{~d} K_{r}}= & {\left[P-W+W M I-P N_{2}^{*}(\gamma+I)\right]\left(\frac{\lambda_{1}+\delta \sigma}{2}-\theta \lambda_{1}-\delta \sigma\right) } \\
& -P(\gamma+I) \frac{\lambda_{1}+\delta \sigma}{2 b_{1}}\left(\delta a+b_{1} N_{2}^{*}-\theta L_{2}^{*}-\delta \sigma K_{r}\right) .
\end{aligned}
$$

To guarantee the benefit of the retailer, we need $\left[P-W+W M I-P N_{2}^{*}(\gamma+I)\right]>0$ and $\delta a+b_{1} N_{2}^{*}-\theta L_{2}^{*}-$ $\delta \sigma K_{r}>0$.

Among them, $\lambda_{1}=\frac{\mathrm{d} L_{2}^{*}}{\mathrm{~d} K_{r}}=\frac{\delta \sigma \theta}{\left(4 b_{1} b_{2}-2 \theta^{2}\right) P(\gamma+I)}>0$. So when $\theta>\frac{1}{2}, \frac{\lambda_{1}+\delta \sigma}{2}-\theta \lambda_{1}-\delta \sigma<0$. That is, $\frac{\mathrm{d} U_{2}^{r^{*}}}{\mathrm{~d} K_{r}}<0$. When the retailer is risk neutral, $K_{r}=0$. Thus $U_{2}^{r^{*}}<U_{1}^{r^{*}}$ is guaranteed, proving Corollary 5.5(1).

Based $U_{2}^{m^{*}}$, we can get

$$
\begin{aligned}
\frac{\mathrm{d} U_{2}^{m^{*}}}{\mathrm{~d} K_{r}}= & {[W-C-W M(\gamma+I)]\left(\frac{\lambda_{1}+\delta \sigma}{2}-\theta \lambda_{1}\right)(W \gamma+P I) \lambda_{1}\left(a-\delta a+b_{2} L_{2}^{*}-\theta N_{2}^{*}\right) } \\
& +\left[W-C-L_{2}^{*}(W \gamma+P I)\right]\left(b_{2} \lambda_{1}-\frac{\theta \lambda_{1}+\theta \delta \sigma}{2 b_{1}}\right) .
\end{aligned}
$$

So when

$$
\left(b_{2} \lambda_{1}-\frac{\theta \lambda_{1}+\theta \delta \sigma}{2 b_{1}}\right)>-(W \gamma+P I) \lambda_{1}\left(a-\delta a+b_{2} L_{2}^{*}-\theta N_{2}^{*}\right)
$$

$\frac{\mathrm{d} U_{2}^{m^{*}}}{\mathrm{~d} K_{r}}>0$ is obtained.

When the retailer is risk neutral, $K_{r}=0$. We can get $U_{2}^{m^{*}}<U_{1}^{m^{*}}$, which proves Corollary 5.5(2).

Proof of Corollary 5.6. Similar to the proof of Propositions 5.1 and 5.3.

Proof of Corollary 5.7. From $N_{3}^{*}$ and $L_{3}^{*}, \frac{\mathrm{d} L_{3}^{*}}{\mathrm{~d} K_{m}}=\frac{2 b_{1}(1-\delta) \sigma}{4 b_{1} b_{2}-2 \theta^{2}}>0$ can be easily obtained. When $\frac{\mathrm{d} N_{3}^{*}}{\mathrm{~d} K_{m}}=$ $\frac{(1-\delta) \sigma}{4 b_{1} b_{2}-2 \theta^{2}}>0, \frac{\mathrm{d} L_{3}^{*}}{\mathrm{~d} K_{m}}-\frac{\mathrm{d} N_{3}^{*}}{\mathrm{~d} K_{m}}=\frac{\left(2 b_{1}-1\right)(1-\delta) \sigma}{4 b_{1} b_{2}-2 \theta^{2}}$. If $b_{1}>1 / 2$, then $\frac{\mathrm{d} L_{3}^{*}}{\mathrm{~d} K_{m}}>\frac{\mathrm{d} N_{3}^{*}}{\mathrm{~d} K_{m}}$ which proves Corollary 5.7.

Proof of Corollary 5.8. From $U_{3}^{m^{*}}$, we have

$$
\begin{aligned}
\frac{\mathrm{d} U_{3}^{m^{*}}}{\mathrm{~d} K_{r}}= & {[W-C-W M(\gamma+I)]\left(\frac{(1-2 \theta) b_{1}(1-\delta) \sigma}{4 b_{1} b_{2}-2 \theta^{2}}-\delta \sigma\right) } \\
& -(W \gamma+P I) \frac{2 b_{1}(1-\delta) \sigma}{4 b_{1} b_{2}-2 \theta^{2}}\left[a-\delta a+b_{2} L_{3}^{*}-\theta N_{3}^{*}-(1-\delta) \sigma K_{m}\right] \\
& +\left[W-C-L_{3}^{*}(W \gamma+P I)\right] \frac{\left(2 \theta^{2}-2 b_{1} b_{2}-\theta\right)(1-\delta) \sigma}{4 b_{1} b_{2}-2 \theta^{2}} .
\end{aligned}
$$

When $\theta>\frac{1}{2}, \frac{(1-2 \theta) b_{1}(1-\delta) \sigma}{4 b_{1} b_{2}-2 \theta^{2}}<0$; therefore, $\frac{\mathrm{d} U_{3}^{m^{*}}}{\mathrm{~d} K_{m}}<0$. When the manufacturer is risk neutral, $K_{m}=0$; then $U_{3}^{m^{*}}<U_{1}^{m^{*}}$, which proves Corollary 5.8(1). Based on $U_{3}^{r^{*}}$, we have

$$
\begin{aligned}
\frac{\mathrm{d} U_{3}^{r^{*}}}{\mathrm{~d} K_{m}}= & {\left[P-W+W M I-P N_{3}^{*}(d+I)\right] \frac{(1-2 \theta) b_{1}(1-\delta) \sigma}{4 b_{1} b_{2}-2 \theta^{2}} } \\
& -P(d+I) \frac{(1-\delta) \sigma}{4 b_{1} b_{2}-2 \theta^{2}}\left(\delta a+b_{1} N_{3}^{*}-\theta L_{3}^{*}\right) .
\end{aligned}
$$


If $\theta>\frac{1}{2}, \frac{(1-2 \theta) b_{1}(1-\delta) \sigma}{4 b_{1} b_{2}-2 \theta^{2}}<0$; then $\frac{\mathrm{d} U_{3}^{r *}}{\mathrm{~d} K_{m}}<0$. When the manufacturer is risk neutral, $K_{m}=0$ thus $U_{3}^{r^{*}}<U_{1}^{r^{*}}$, which proves Corollary 5.8(2).

Proof of Proposition 5.9. Similar to the proof of Propositions 5.1 and 5.3.

Proof of Corollary 5.10. From $N_{4}^{*}$ and $L_{4}^{*}, \frac{\mathrm{d} L_{4}^{*}}{\mathrm{~d} K_{r}}=\frac{\delta \sigma \theta}{4 b_{1} b_{2}-2 \theta^{2}}>0$ can be found. Then $\frac{\mathrm{d} L_{4}^{*}}{\mathrm{~d} K_{m}}=\frac{2 b_{1}(1-\delta) \sigma}{4 b_{1} b_{2}-2 \theta^{2}}>0$ $\frac{\mathrm{d} N_{4}^{*}}{\mathrm{~d} K_{r}}=\frac{\delta \sigma}{2 b_{1}}+\frac{\delta \sigma \theta}{2 b_{1}\left(4 b_{1} b_{2}-2 \theta^{2}\right)}>0$, and $\frac{\mathrm{d} N_{4}^{*}}{\mathrm{~d} K_{m}}=\frac{2 b_{1}(1-\delta) \sigma}{2 b_{1}\left(4 b_{1} b_{2}-2 \theta^{2}\right)}>0 ; L_{4}^{*}>L_{1}^{*}, N_{4}^{*}>N_{1}^{*}$ supporting Corollary 5.10.

Proof of Corollary 5.11. Similar to the proof of Corollaries 5.5 and 5.8.

Proof of Corollary 5.12. From $N_{i}^{*}$ and $L_{i}^{*}$ in Table $2, N_{4}^{*}>N_{3}^{*}>N_{1}^{*}, N_{4}^{*}>N_{2}^{*}>N_{1}^{*}$ can be found. Comparing $N_{2}^{*}$ with $N_{3}^{*}$, it can be seen that when $\delta<\frac{2 b_{1} K_{m}}{\left(4 b_{1} b_{2}-2 \theta^{2}\right) K_{r}+2 b_{1} K_{m}}$, the relationship between the delayed payment period of the four decision instances is $N_{4}^{*}>N_{3}^{*}>N_{2}^{*}>N_{1}^{*}>0$, which proves Corollary 5.12.

Proof of Corollary 5.13. Similar to the proof of Corollary 5.13.

Proof of Proposition 6.1. Similar to the proof of Propositions 5.1 and 5.3.

Proof of Corollary 6.2. Corollary 6.2 can be obtained through equation (6.5).

Acknowledgements. The authors greatly appreciate the editor and the anonymous referees for their insightful comments and suggestions that have significantly improved the paper. The research has been supported by the National Natural Science Foundation of China (71301079), supported by the Humanity and Social Science Youth Foundation of Ministry of Education of China (18YJC630235).

\section{REFERENCES}

[1] K.A. Arshinder and S.G. Deshmukh, Supply chain coordination: perspectives, empirical studies and research directions. Int. J. Prod. Econ. 115 (2008) 316-335.

[2] Q. Bai, J. Xu and Y. Zhang, Emission reduction decision and coordination of a make-to-order supply chain with two products under cap-and-trade regulation. Comput. Ind. Eng. 119 (2018) 131-145.

[3] Q. Bai, J. Xu and S.S. Chauhan, Effects of sustainability investment and risk aversion on a two-stage supply chain coordination under a carbon tax policy. Comput. Ind. Eng. 142 (2020) 106324.

[4] S. Bollapragada and T.E. Morton, Myopic heuristics for the random yield problem. Oper. Res. 47 (1999) $713-722$.

[5] T. Boyaci, Competitive stocking and coordination in a multiple-channel distribution system. IIE Trans. 37 (2005) $407-427$.

[6] G.P. Cachon, Channel selection and coordination in dual-channel supply chains. Handb. Oper. Res. Manage. Sci. 11 (2003) $227-339$.

[7] G. Cai, Channel selection and coordination in dual-channel supply chains. J. Retail. 86 (2010) 22-36.

[8] J. Chen, H. Zhang and Y. Sun, Direct marketing, indirect profits: a strategic analysis of dual-channel supply-chain design. Manage. Sci. 49 (2003) 1-20.

[9] J. Chen, H. Zhang and Y. Sun, Implementing coordination contracts in a manufacturer Stackelberg dual-channel supply chain. Omega 40 (2012) 571-583.

[10] W.Y.K. Chiang, Product availability in competitive and cooperative dual-channel distribution with stock-out based substitution. Eur. J. Oper. Res. 200 (2010) 111-126.

[11] C. Chiu and T. Choi, Supply chain risk analysis with mean-variance models: a technical review. Ann. Oper. Res. 240 (2016) 489-507.

[12] T.M. Choi, D. Li, H. Yan and C.H. Chiu, Channel coordination in supply chains with agents having mean-variance objectives. Omega 36 (2008) 565-576.

[13] T.M. Choi, C. Ma, B. Shen and Q. Sun, Optimal pricing in mass customization supply chains with riks-averse agents and retail competition. Omega 88 (2019) 150-161.

[14] Circuit City Stores, Inc., Circuit City bankruptcy petition. Available at http://www.creditslips.org/creditslips/ CircuitCity.pdf. Accessed date: 15 June 2013 (2008). 
[15] B. Dan, G. Xu and C. Liu, Pricing policies in a dual-channel supply chain with retail services. Int. J. Prod. Econ. 139 (2012) $312-320$.

[16] X. Gan, S. P. Sethi and H. Yan, Channel coordination with a risk-neutral supplier and a downside-risk-averse retailer. Prod. Oper. Manage. 14 (2010) 80-89.

[17] Q. Geng and S. Mallik, Inventory competition and allocation in a multi-channel distribution system. Eur. J. Oper. Res. 182 (2007) 704-729.

[18] C.H. Glock, K. Schwindl and J.M. Ries, A note on: optimal ordering policy for stock-dependent demand under progressive payment scheme. Eur. J. Oper. Res. 232 (2013) 423-426.

[19] K. Govindan, M.N. Popiuc and A. Diabat, Overview of coordination contracts within forward and reverse supply chains. J. Clean Prod. 47 (2013) 319-334.

[20] S.K. Goyal, Economic order quantity under conditions of permissible delay in payments. J. Oper. Res. Soc. 39 (1988) $322-323$.

[21] R. He, Y. Xiong and Z. Lin, Carbon emissions in a dual channel closed loop supply chain: the impact of consumer free riding behavior. J. Clean Prod. 134 (2016) 384-394.

[22] G.W. Hua, S.Y. Wang and T.C.E. Cheng, Price and lead time decisions in dual-channel supply chains. Eur. J. Oper. Res. 205 (2010) 113-126.

[23] Z. Hua, X. Zhang and X. Xu, Product design strategies in a manufacturer-retailer distribution channel. Omega 39 (2011) $23-32$.

[24] Y.F. Huang, Optimal retailer's ordering policies in the EOQ model under trade credit financing. J. Oper. Res. Soc. 54 (2003) $1011-1015$.

[25] Y.F. Huang, Optimal retailer's replenishment decisions in the EPQ model under two levels of trade credit policy. Eur. J. Oper. Res. 176 (2007) 1577-1591.

[26] W. Huang and J.M. Swaminathanab, Introduction of a second channel: implications for pricing and profits. Eur. J. Oper. Res. 194 (2009) 258-279.

[27] M. Huang, M. Song, L.H. Lee and W.K. Ching, Analysis for strategy of closed-loop supply chain with dual recycling channel. Int. J. Prod. Econ. 144 (2013) 510-520.

[28] J. Hurley, Biggest firms improving payment times. Telegraph (October 29). Available at http://www.telegraph.co.uk/ finance/businessclub/9641361/Biggest-firms-improving-payment-times.html (2012).

[29] D. Kahneman and A. Tversky, Prospect theory: analysis of decision under risk. Econometrica 47 (1979) $263-291$.

[30] M. Khouja, S. Park and G. Cai, Channel selection and pricing in the presence of retail-captive consumers. Int. J. Prod. Econ. 125 (2010) 84-95.

[31] K.K. Kim and K.S. Park, Transferring and sharing exchange-rate risk in a risk-averse supply chain of a multinational firm. Eur. J. Oper. Res. 237 (2014) 634-648.

[32] L. Klapper, L. Laeven and R. Rajan, Trade credit contracts. Rev. Financ. Stud. 25 (2010) 838-867.

[33] V.B. Kreng and S.J. Tan, The optimal replenishment decisions under two levels of trade credit policy depending on the order quantity. Expert Syst. Appl. 37 (2010) 5514-5522.

[34] X. Lang, W. Chuanxu and Z. Junjie, Decision and coordination in the dual-channel supply chain considering cap-and-trade regulation. J. Clean Prod. 197 (2018) 551-561.

[35] H.H. Lee, J. Zhou and J. Wang, Trade credit financing under competition and its impact on firm performance in supply chains. Manuf. Serv. Oper. Manage. 20 (2017) 36-52.

[36] B. Li, P. Chen, Q. Li and W. Wang, Dual-channel supply chain pricing decisions with a risk-averse retailer. Int. J. Prod. Res. 52 (2014) 7132-7147.

[37] B. Li, P.W. Hou, P. Chen and Q.H. Li, Pricing strategy and coordination in a dual channel supply chain with a risk-averse retailer. Int. J. Prod. Econ. 178 (2016) 154-168.

[38] B. Liu, R. Zhang and M. Xiao, Joint decision on production and pricing for online dual channel supply chain system. Appl. Math. Model. 34 (2010) 4208-4218.

[39] Y. Liu, Z. Fan and Y. Zhang, Risk decision analysis in emergency response: a method based on cumulative prospect theory. Comput. Oper. Res. 42 (2014) 75-82.

[40] M. Liu, E. Cao and C.K. Salifou, Pricing strategies of a dual-channel supply chain with risk aversion. Transp. Res. Pt. e-Logist. Transp. Rev. 90 (2016) 108-120.

[41] G. Liu, T. Yang, Y. Wei and X. Zhang, Decisions on dual-channel supply chains under market fluctuations and dual-risk aversion. Discrete Dyn. Nat. Soc. (2020). DOI: 10.1155/2020/2612357.

[42] K.R. Lou and W.C. Wang, Optimal trade credit and order quantity when trade credit impacts on both demand rate and default risk. J. Oper. Res. Soc. 64 (2013) 1551-1556.

[43] H. Markowitz, Portfolio Selection: Efficient Diversification of Investment. Yale University Press, New Haven, NH (1970).

[44] H. Peura, S.A. Yang and G. Lai, Trade credit in competition: a horizontal benefit. Manuf. Serv. Oper. Manage. 19 (2017) 263-289.

[45] Q. Qi, W. Jing and X. Jianteng, A dual-channel supply chain coordination under carbon cap-and-trade regulation. Int. J. Environ. Res. Publ. Health 15 (2018) 1316.

[46] J. Qin, A. Zhang, L. Xia and M. Liu, Retail order-taking strategies under competing trade credit policies with varying demands. Asia Pac. J. Oper. Res. 34 (2017) 1-17.

[47] T.A. Taylor, Supply chain coordination under channel rebates with sales effort effects. Manage. Sci. 48 (2002) $992-1007$. 
[48] J.T. Teng, On the economic order quantity under conditions of permissible delay in payments. J. Oper. Res. Soc. 53 (2002) $263-289$.

[49] J.T. Teng, K.R. Lou and L. Wang, Optimal trade credit and lot size policies in economic production quantity models with learning curve production costs. Int. J. Prod. Econ. 155 (2014) 915-918.

[50] Y.C. Tsao, Channel coordination under two-level trade credits and demand uncertainty. Appl. Math. Model. 52 (2017) $160-173$.

[51] A.A. Tsay and N. Agrawal, Channel conflict and coordination in the e-commerce age. Prod. Oper. Manage. 13 (2009) 93-110.

[52] A. Tversky and D. Kahneman, Loss aversion in riskless choice: a reference-dependent model. Q. J. Econ. 106 (1991) $1039-1061$.

[53] Vandana and A. Kaur, Two-level trade credit with default risk in the supply chain under stochastic demand. Omega 88 (2019) $4-23$.

[54] Y. Wei and T. Choi, Mean-variance analysis of supply chains under wholesale pricing and profit sharing schemes. Eur. J. Oper. Res. 204 (2010) 255-262.

[55] J. Wu, S. Wang, X. Chao, C.T. Ng and T.C.E. Cheng, Impact of risk aversion on optimal decisions in supply contracts. Int. J. Prod. Econ. 128 (2010) 569-576.

[56] C. Wu, Q. Zhao and M. Xi, A retailer-supplier supply chain model with trade credit default risk in a supplier-Stackelberg game. Comput. Ind. Eng. 112 (2017) 568-575.

[57] G. Xie, W. Yue, S. Wang and K.K. Lai, Quality investment and price decision in a risk-averse supply chain. Eur. J. Oper. Res. 214 (2011) 403-410.

[58] H. Xu, Z.Z. Liu and S.H. Zhang, A strategic analysis of dual-channel supply chain design with price and delivery lead time considerations. Int. J. Prod. Econ. 139 (2012) 654-663.

[59] G. Xu, B. Dan, X. Zhang and C. Liu, Coordinating a dual-channel supply chain with risk-averse under a two-way revenue sharing contract. Int. J. Prod. Econ. 147 (2014) 171-179.

[60] W. Xue, T. Choi and L. Ma, Diversification strategy with random yield suppliers for a mean-variance risk-sensitive manufacturer. Transp. Res. Pt. e-Logist. Transp. Rev. 90 (2016) 90-107.

[61] X. Yan, S. Du and L. Hu, Supply chain performance for a risk inequity averse newsvendor. Ann. Oper. Res. (2020) 897-921.

[62] S.A. Yang and J.R. Birge, Trade credit, risk sharing, and inventory financing portfolios. Manage. Sci. 64 (2017) $3667-3689$.

[63] D.Q. Yao and J.J. Liu, Competitive pricing of mixed retail and e-tail distribution channels. Omega 33 (2005) $235-247$.

[64] P. Yi, M. Huang, L. Guo and T. Shi, Dual recycling channel decision in retailer oriented closed-loop supply chain for construction machinery remanufacturing. J. Clean Prod. 137 (2016) 1393-1405. 